DIW BERLIN

Discussion

Papers
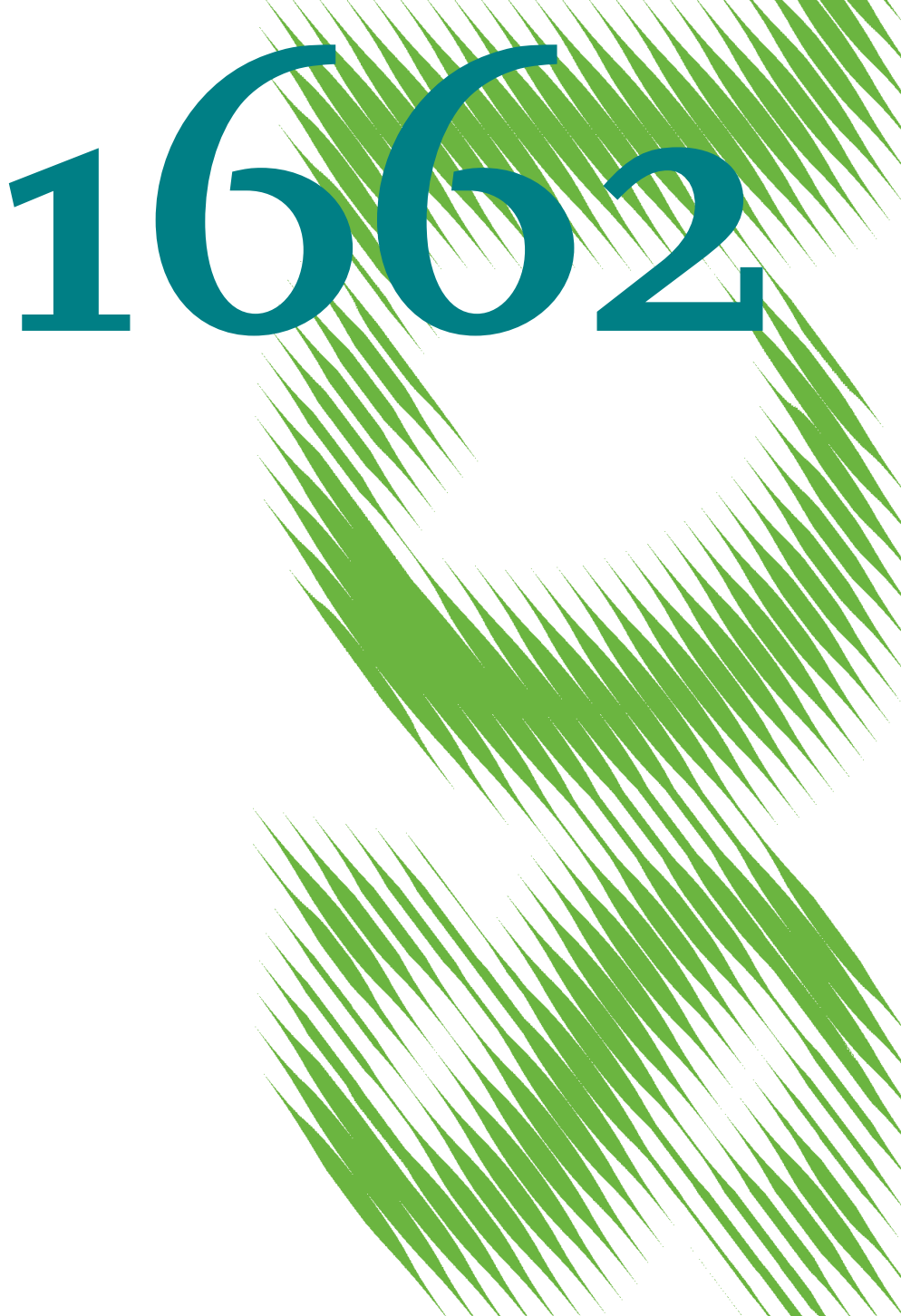

111

Why Do Women Favor Same-Gender Competition?

Evidence from a Choice Experiment 
Opinions expressed in this paper are those of the author(s) and do not necessarily reflect views of the institute.

IMPRESSUM

(C) DIW Berlin, 2017

DIW Berlin

German Institute for Economic Research

Mohrenstr. 58

10117 Berlin

Tel. +49 (30) $89789-0$

Fax +49 (30) $89789-200$

http://www.diw.de

ISSN electronic edition 1619-4535

Papers can be downloaded free of charge from the DIW Berlin website:

http://www.diw.de/discussionpapers

Discussion Papers of DIW Berlin are indexed in RePEc and SSRN:

http://ideas.repec.org/s/diw/diwwpp.html

http://www.ssrn.com/link/DIW-Berlin-German-Inst-Econ-Res.html 


\title{
Why Do Women Favor Same-Gender Competition? Evidence From a Choice Experiment*
}

\author{
Norma Burow ${ }^{\dagger}$ Miriam Beblo; Denis Beninger
}

This version April 2017

\begin{abstract}
This paper addresses the behavioral puzzle of women's preference for competition when competitors are also women. Using a framed field experiment with 883 non-standard subjects, we show that none of the determinants of competitive behavior in general, including ability, self-confidence, and risk aversion, provide a satisfying explanation for women's substantive gender-related selection into competition. Nonetheless, women who are overconfident, i.e. over-estimate own abilities in performing a task, enter competition regardless of the gender-mix. Hence, the gender-pairing phenomenon is driven by women who correctly estimate or under-estimate own ability. We conclude that this is due to stereotypes about women's underperformance compared to men.
\end{abstract}

Keywords: preferences for competition; gender; group composition; self-confidence

JEL: C99, D83, J16

${ }^{*}$ We are grateful to participants at conferences, seminars, and workshops in e.g. Berlin (BEgender@DIW, IAFFE), Heidelberg (ESA), Konstanz (GSDS Symposium "Attitudes and Preferences"), Ljubljana (EALE), and Toulouse (IMEBESS). In particular, we thank Manuel Bagues, Friedel Bolle, David Danz, Alexandra Fedorets, Luise Görges, Dorothea Kübler, Philipp E. Otto, Eva Ranehill, Thomas Siedler, Natalia Zinovyeva for helpful comments and Adam Lederer for valuable assistance. We acknowledge the financial support by the German Ministry BMBF and ESF of the European Union. All remaining errors are our own.

${ }^{\dagger}$ DIW Berlin/Germany, email: nburow@diw.de

${ }^{\ddagger}$ Universität Hamburg/Germany

$\S_{\text {University of Strasbourg/France }}$

${ }^{\mathbb{I}}$ Wissenschaftliches Institut der AOK, Berlin/Germany 


\section{Introduction}

"Are women prejudiced against women?" (Goldberg, 1968) has not only been asked by the early literature. There is growing interest at least since the pioneering study by Gneezy et al. (2003) who find a gender gap in competition with women increasing their productivity in a competitive setting only when their opponents are also women. They additionally observe a gender gap in performance in a mixed-gender tournament that is larger than in any other tournament. Niederle et al. (2013) also observe such effects at selection into competition. At the same time, Datta Gupta et al. (2013) find that given the opportunity to choose their opponent's gender, women's competition willingness increases significantly. Booth \& Nolen (2012a), studying the behavior of school girls, find that girls compete equally likely as boys when in a same-gender setting.

In the same vein in the lab and in other domains, studies observe similar gender-pairing effects in ultimatum (Eckel \& Grossman, 2001), dictator (Ben-Ner et al., 2004), multistage alternatingoffer bargaining (Dittrich et al., 2014), and in all-pay auction games (Chen et al., 2015). While there seems to be evidence on women's economic decision-making being affected by the gender of the party with whom they are interacting, explanations regarding women's preferences for same-gender competition are rather rare. Our paper addresses this behavioral puzzle and goes beyond the existing research by focusing on explanations already given for women's (compared to men) restrained competition behavior 11 We check whether (1) ability to solve a specific type of task; (2) self-confidence; (3) being over-confident with respect to own ability; or even (4) risk-willingness might explain a preference for same-gender competition.

To achieve this, we conduct a choice experiment in a framed field setting, which we combine with a real effort task in order to elicit individual preferences toward competition when the gender-mix of the competitors group varies exogenously. We track more than twenty withinperson choices, which are all taken in payoff relevant choice sets that ruled different wage vectors, difficulty levels of the later task, as well as the presence of competition. A choice experiment in this novel form taking over a revealed preferences approach allows a more comprehensive view of a person's preferences.

This approach has several advantages: First, we can directly investigate the effect of genderpairing for competition, since each subject faces two different exogenously assigned genderpairing decision settings, all else being equal. Second, our design allows us to reveal whether a person is over-confident in their own ability by referring to the concept of self-estimation, which is a subform of self-confidence with the advantage of not depending on assessing others' ability (Moore \& Healy, 2008; Olsson, 2014)). It allows us to detect how a person relates her knowledge of how good she is in solving this type of task to choices in competition-free settings and to compare that choice behavior to otherwise identical competition-involving settings. Third, since subjects get to know their ability in solving this type of task with practice, we can demonstrate that stereotypical beliefs regarding a gender gap in ability determine women's preference toward same-gender competition.

Our main results are as follows: (1) We find robust evidence for women's exceptionally increased

\footnotetext{
${ }^{1}$ See Niederle \& Vesterlund (2007), Niederle \& Vesterlund (2011) and Kamas \& Preston (2012).
} 
willingness to compete in same-gender environments, while we find no gender-pairing effects for men. (2) A gender gap in competition willingness is only present in a mixed-gender setting, but is eliminated for self-confident as well as over-confident subjects. (3) While self-confidence itself is a basic prerequisite for the propensity to compete in general for men and women, (4) we demonstrate that an average woman who is over-confident in her own ability no longer prefers same-gender over mixed-gender competition as she equally likely engages too frequently in competition, not depending her decision on the gender-mix. Hence, overconfident women build exactly that group where same-gender is no longer the dominant group composition, which determines women's competition behavior. The gap between mixed- and same-gender is only present for women whose self-estimation is correct or low: they restrain from mixed-gender competition but compete too much in same-gender competition. (5) neither ability, nor selfconfidence, nor risk aversion provide additional inside into explaining this gap. Therefore, we suggest that a gender stereotype about the performance of women and men dominates women's beliefs and actions; a stereotype that deters the beliefs that a women-plus-men group must outperform a women-only group.

Our experiment provides a comprehensive view in that it reveals both gender-pairing related competition preferences and self-confidence. In addition, it applies a big anonymous competition group that is closer to reality. Apart from that, the subject pool in our experiment is different from previous studies. As opposed to most previous studies on gender differences in preferences, which are conducted using non-probabilistic student samples (see for an overview Niederle, 2016), we use a probabilistic non-student sample. This approach is comparable to Boschini et al. (2014), who use a representative sample of the Swedish population to study gender differences in preferences in several domains like e.g. competition, risk-taking behavior, and generosity. Others studying gender-pairing effects on competition preferences use school students (UK: Booth \& Nolen, 2012a, South Korea: Lee et al., 2014). In addition, since we use a probabilistic non-student sample, we can define a subsample of the full-time employed women population in Germany that does not differ with respect to income, education, or risk-willingness. We could, therefore, incorporate empirical evidence on the crucial question of more generalizability regarding behavioral differences.

Another strength of our experiment is that we are able to simulate a real world setting, which is comparable to a job application situation, in which an individual has to decide to compete against an anonymous group of other applicants. Such situation is characterized by total anonymity, uncertainty about the total number of applicants, as well as their genders. We provide a large competition group (larger than in previous studies in which group size is only at maximum up to 6), which is totally unknown in size and gender composition to the individual participant. Information about gender is usually realized in other studies via seeing others in order to ensure that subjects could determine others' gender, without causing priming or experimenter demand effects (Niederle, 2016). This comes at the expense of setting aside anonymity. In our study we realized total anonymity since at no point in time could participants see each other or receive information other than that which was provided about gender in written form. This is indeed comparable to real situations, in which people think whether to take part or not. The setting is more or less the same: a large, unknown group with the individual being anonymous. If a 
person is then informed about the preferable treatment of a certain group like women, e.g. a quota for women, then this situation is similar to our setting of a same-gender competition with other women as the only competitors.

The remainder of the paper is set out as follows: Section 2 reviews the relevant literature. Section 3 describes the design of the experiment and the logistics. Section 4 is devoted to the experimental results followed by Section 5 for a short discussion and conclusion. The Appendices contain further information about the experiment and descriptive statistics.

\section{Literature Review and Conjectures}

The literature regarding gender-pairing effects dates back to Goldberg (1968), who finds that women in the role of reviewers perceive articles written by women to be inferior. Broder (1993) confirms this finding when investigating whether this phenomenon also exists for the review of economics proposals for NSF grants in the US. In addition, Bagues \& Esteve-Volart (2010), who study appointment decisions to the Spanish Judiciary with survey data, support this finding, showing that women have a lower probability to be granted when the evaluation committee, although randomly assigned, consists mostly of women. Newton \& Simutin (2014) add to the literature on gender-pairing by showing that the gender-pairing even in a wage-setting context matters.Broder (1993) suggests that this phenomenon is comparable to a competitive setting, which is characterized by scarce resources that are allocated to women and in which women evaluate women more harshly than men.

On the basis of experimental methods, there are many studies exploring gender-pairing effects in different domains in controlled settings. An early study is Rapoport \& Chammah (1965), which finds that female pairs in a dictator game are less likely to play cooperatively than male pairs. This is confirmed by Ben-Ner et al. (2004), who show that female dictators send less to other women than to men or people of unknown gender. Dittrich et al. (2014) demonstrate that women negotiate lower wages, supported by Sutter et al. (2009) who find that a generally lower efficiency level is reached in a same-gender setting. Di Cagno et al. (2016) find women acting as sellers are more likely to overstate the firm's value if they are confronted by a female buyer. In the same vein, Eckel \& Grossman (2001) observe same-gender effects in ultimatum games with respect to women's generally higher generosity level compared to men, but lower generosity level toward other women.

Apart from these experimental games, gender-pairing effects are also investigated in competitive environments. Our study is most closely related to studies by Booth \& Nolen (2012a) and Datta Gupta et al. (2013), both focusing explicitly on selection into competition when varying the gender of the opponent in a between-subjects design. Booth \& Nolen (2012a) study the behavior of students and find that girls are as likely as boys to compete in a same-gender setting if they come from a same-gender school, but not if they come from a mixed-gender school. Datta Gupta et al. (2013), however, studying behavior of undergraduates, only find a direct effect of knowing opponent's gender on men's behavior. While they observe women increasing their competitiveness when offered the opportunity to choose opponent's gender to be female, as 
opposed to a situation in which opponent's gender is predetermined to be female. Apicella et al. (forthcoming) who distinguish between other and self-competition find in their same-gender setting still a significant gender gap in the willingness to compete.

Evidence for women's presumably reluctant competition willingness when comparing with men deals with gender gaps (1) in the ability to solve a specific type of task; (2) in self-confidence, particularly (3) women lacking behind men's over-confidence; and (4) in risk-taking behavior ${ }^{2}$ We suggest checking the power of these explanations for women's general competition preferences in order to provide insights on their same-gender preferences.

With regard to ability, we assume that people take a payoff-maximizing choice, subject to all available information, basing their decision for entering a competitive situation first and foremost on their preferences to compete and the information about their own absolute ability as the probability to win is positively related to a person's own ability. Additionally, as the probability to win is negatively related to the ability of their opponents, their decision is also based on the perception of others' ability, hence their own relative ability (Butler, 2016). Gender may be seen as an indicator - a signal - of ability (Gneezy et al., 2003), at least stereotypically from the point of view that a group of the same gender is also believed to be a more homogenous group with comparable ability to one's own ability (Booth \& Nolen, 2012a).

Concerning a person's self-confidence, it is well-documented in the literature that it is an important factor for selection into competitive situations. However, we know from the literature that women are, on average, less self-confident than men (see i.a. Niederle \& Vesterlund, 2007). Therefore, it is reasonable to assume that they are also less likely to compete. This is supported by Brandts et al. (2015) who confirm that a lack of self-confidence in own relative ability negatively affects the decision to compete. Why is this relevant in our context? Changing the opponent's gender should not make a difference at all, but Niederle et al. (2013) mention a gender gap in the beliefs in relative ability that is present in mixed but not in single-gender groups. This is in line with Datta Gupta et al. (2013), who demonstrate that the gap in competition willingness is reduced when women can choose the gender of their opponents. This seems to imply that the information about gender spurs subjective beliefs about the probability to win, which in turn might be based on stereotypes (Kamas \& Preston, 2012). As Bordalo et al. (2016) argue for their formalization of stereotypes' effects, women might underestimate their probabilities to win in the presence of men, so that it could be inferred that they correctly estimate them in a same-gender environment.

Following Kamas \& Preston (2012), the gender gap in self-confidence is particularly pronounced if it is measured as self-placement - a subform of self-confidence - that is nothing less than an expression of the self-assessment of own relative ability 3 Thus, in order to determine the participants' self-confidence in a setting that is free from potential gender bias, we implement a

\footnotetext{
${ }^{2}$ See Niederle \& Vesterlund (2007), Niederle \& Vesterlund (2011) and Kamas \& Preston (2012). For a critique on generalizing statements concerning gender differences see Nelson (2014).

${ }^{3}$ The phenomenon of over-confidence is widely researched in the field of economics, but not always consistently. Moore \& Healy (2008) shed light on how self-confidence is defined differently as (1) as self-estimation of one's own achievements, performance, etc.; (2) as self-placement (better-than-average-effect in case of over-placement) as relatively estimating one's own achievements compared to others; or (3) as self-precision as the degree of certainty about the accuracy of one's beliefs.
} 
setting that does not require participants to self-assess their own relative ability but rather reveals how they evaluate their own absolute ability without the thrill of competing against others in order to measure self-confidence. According to Niederle \& Vesterlund (2011), this competitionfree setting mimics the risk of competition-involving settings. Over-confidence in our definition measures the correctness of one's self-confidence in that it relates a person's actual own absolute ability with their expressed self-confidence: participants not being discovered as able participants but nevertheless behave self-confidently reveal themselves to be over-confident. With respect to gender-pairing effects, we hypothesize that someone who is self-confident in general or even over-confident about their own absolute ability enters competition anyway without making a difference with respect to the gender-mix.

With regard to risk aversion, women are found to be less risk averse on average than men 4 Since risk-taking behavior is seen as correlating with a person's competition willingness (since competitive situations involve a greater risk/uncertainty compared to non-competitive situations Niederle \& Vesterlund, 2011), it also seems reasonable to expect an average woman to be less competition willing. However, as Niederle \& Vesterlund (2011) summarize, risk preferences only explain a small portion of the general gender gap in competition willingness 5 Further, Booth \& Nolen (2012b) find evidence for the gender-mix to have an effect on girls' risk preferences: girls are revealed to be much less risk averse (enter a lottery more frequently) in a same-gender group. This might again suggest that it is subjective probabilities that matter for choices. As discussed above, subjects might expect different probabilities of winning related to the gendermix of the opponents' group, hence they might evaluate the probability of winning a same-gender tournament much higher. Therefore, if risk aversion affects women's competition willingness in general, we expect it to be less severe in case of a same-gender setting.

\section{Experiment}

For our experiment, we adopted an incentive-compatible choice experimental design to reveal individual's preferences toward competition ${ }^{6}$ In the following, we give logistical information about carrying out the experiment. We then present some theoretical foundations about the nature of choice experiments that we adopt. Implementing this specific technique in our experiment allows us to elicit individual competition preferences at two different gender-related group composition levels, as well as to elicit their self-confidence.

\footnotetext{
${ }^{4}$ However, the evidence for gender differences in risk preferences is not that clear (Niederle, 2016). See Nelson (2014) for a critique on generalizing statements.

Niederle \& Vesterlund (2011) discuss three elicitation methods: (1) revealing risk preferences from choices in settings that do not involve any competition but involve a similar risk; (2) eliciting risk preferences from incentivized lotteries; or (3) from drawing upon stated risk preferences from a questionnaire. Niederle (2016) argues that not every method discloses gender differences and following Niederle \& Vesterlund (2011), the explanatory power of risk preferences depends on which elicitation method is used. In line with this is van Veldhuizen (2016), who argues that the influence of risk is underestimated in much of the literature due to only recognizing it econometrically.

${ }^{6}$ See choice experiments to measure stated preferences and the necessity of incentive-compatibility to reveal preferences within this approach (Harrison, 2007).
} 


\subsection{Logistics}

Using a large subject pool with 883 non-standard subjects, 442 women and 441 men, living across Germany, we implemented an online-based experiment. Participants were randomly sampled following a stratification procedure that recognizes gender, age, marital status, and region. They were recruited from the original data panel of an online research marketing institute, which additionally programmed the online interface following our experimental design as well as other strict requirements. It ran out the experiment, provided us with the participants' decisions and characteristics. Participants were paid by money transfer on their bank account for this experiment only, separately from any payment in money, points or coupons for participating in other surveys by that marketing institute. According to Harrison \& List (2004), our study takes the form of a framed-field experiment because it employs non-standard subjects who took part in a field context. In this manner, an online experiment gave us the chance to study de facto experimentally inexperienced participants in their natural environments, thus avoiding a highly stylistic classroom setting. As laboratory experimental results are already replicated by online experiments, we do not expect validity problems (Edelman, 2012; Horton et al., 2011).

Subjects were invited by email to participate in a scientific study that would take up a maximum of 30 minutes. Two weeks before the actual experiment was conducted, we collected data on socio-economic aspects so that we could balance the sample over gender, marital status (single vs. cohabiting/married), and residential region (East vs. West-Germany) within an age-range of 25 to 51 years (See Table6 in Appendix C). Subjects were also asked to answer a self-reported multi-item risk questionnaire, which we adapted from the SOEP questionnaire 7

The experiment consisted of two parts: Participants first completed a choice experiment that was then followed by a real effort task, which they had to perform. Right at the start of the experiment, subjects were informed that they will earn money by fulfilling tasks, which will be: to solve as many mazes as possible. They were told that their final payment will depend on their performance by this task and their decisions during the experiment, plus an additional lump-sum payment (show-up fee). They were first introduced to the task through two trial mazes (one easy, one hard level), from which they learn about their individual performance in the task, as they were informed about the time they needed to solve both mazes. We further used these times as a proxy for their ability. In the next step, we introduced the type of choices participants have to make and the subsequent payment scheme. The payment conditions are set within the description of binary choice sets. To ensure that participants well understood it, we sequentially presented three sample choice sets with a predetermined option in each. For each set, subjects had to state how much one would potentially earn under these conditions. They could proceed to the choice experimental part once they answered the three test payment calculations correctly.

In the experimental part we then presented multiple binary choice sets combined with real monetary incentives that were performance based. Subjects had to choose one option out of two in every choice set, knowing that their choice is relevant for their earnings. In total, we presented 23 choice sets - each separately and sequentially in the same order for each subject

\footnotetext{
${ }^{7}$ Regarding the validity of stated risk preferences see also Dohmen et al. (2011); Lönnqvist et al. (2015).
} 
with two options. The choice sets were presented in a clear and deliberate fashion so that every subject had the chance of correctly understanding and responding to it, no matter if the choice set was placed late or based on the individual cognitive abilities. Different attributes of the compensation scheme were varied along the choice sets so that participants had to decide which attribute was more important to them. Participants were again informed that (1) their payments will be determined by the conditions that were set by the individually chosen option of that specific choice set, which will be (2) drawn at random directly after having completed all choices and (3) prior to starting the task and performance part.

In the second part of the experiment, participants were informed about which choice set was randomly chosen and, hence, which is the related chosen payment option. Thus, they learned under what conditions they would have to solve the real-effort task in order to get paid. After having solved mazes for 5 minutes, each participant is informed about the number of mazes she has solved. Participants who performed under the condition of competition were informed about their two possible final payoffs, which depend on their relative group ranking that, due to the fact that other participants could take part at different times, is not determined yet. Nonetheless, they receive the information about their payoff in the case they rank among the top third (they won) and in the case they do not (they lost).

After the experiment, the participants were asked to fill out a post-experimental questionnaire on socio-economic aspects and on social values regarding gender-specific job attributes as well as on self-reported risk attitudes, as in the pre-experimental study.

\subsection{Design}

Our choice experiment presents a way to obtain a comprehensive view of an individual's preferences toward competition. The design has the advantage over the usual design of choice experiments in that it does not deal with hypothetical scenarios. Consequently, it combines the framework of a choice experiment with an incentive-compatible real effort task and, as such, follows a revealed preferences logic (Harrison, 2007). Revealed choice experiments follow the rational choice approach: choosing the alternative that maximizes utility ${ }^{8}$

In our choice experiment, we provided each option with a maximum of four attributes with two relating dimensions each: Difficulty (easy vs. hard), performance (linear vs. threshold), competition ('no' vs. 'yes' against either a same-gender or a mixed-gender competition group), and wage spread (low vs. high). The wage was constructed as a performance pay, i.e. a piece rate wage, that each participant could earn depending on the chosen option as the basis for the final payoff. Option A provides for a risk-neutral individual a lower expected value as opposed to option $\mathrm{B} 9^{9}$ When an option involves competition, the individual performance is set in relation to the competition group's average performance. However, only those who choose option B decide to compete, which means that they evaluate themselves as being able to place themselves

\footnotetext{
${ }^{8}$ See the terminology by Harrison $(2007)$; also found in Buckley et al. 2012

${ }^{9}$ See the exception of choice set \#3, \#4, and \#23 in Appendix B. Nonetheless, option B in choice sets \#3 and \#4 is still the more demanding option because it additionally requires an estimation of others' ability. Choice set \#23 is introduced for a rationality check and, thus, reverses the usual design of option A and B.
} 
among the best top third of the performance distribution of the total group (mixed-gender) or only a subgroup of all participants (same-gender) and thus to benefit by receiving the higher piece-rate wage. Thus, the decision to compete is coincidentally a decision under the risk of not being among the top third and ending up with a lower piece-rate wage than from having chosen the non-competition option A. We additionally varied the spread of the wage vector in order to vary the risk premium: wages for choice sets with a higher wage spread implied a higher expected value together with a greater variance compared to a low spread environment. Meaningful combinations plus a rationality check with a reversed wage and difficulty relation yield 23 choice sets 10 Since every choice set was relevant for payment and drawn by random at the end of the experiment, we ensured an incentive compatible choice experiment (Harrison, 2007).

We assume choice sets with a higher spread of wages to involve higher opportunity costs since the difference between the lower bound of the wage range of choosing option $\mathrm{B}$ and the forgone certain (not chosen option A) wage is higher than in choice sets with a low spread of wage. What is more, while the uncertainty of estimating others' abilities is independent from the wage spread, a high wage spread involves a higher variance - hence, the risk of failing to an even lower wage level is high too. Therefore, we take a high wage spread choice set to be a proxy for a higher risk involving environment.

Revealing beliefs about gender-based perceptions about a gender gap in the ability to solve mazes is based on the assumption of payoff maximization: Thus, subjects' choices will reveal whether a subject has the belief or is convinced that she, herself, is able to meet the specific conditions of Option B: meets the threshold of 5 mazes implemented in Option B of choice sets \#5 to \#10 (group 3, reveal self-confidence and over-confidence) or could place herself among the top third of a mixed-gender group (group 4, choice sets \#11-\#16) or a same-gender group (group 5, choice sets \#17-\#22) (reveal competition and group composition preferences).

Due to a random assignment of the choice set and, thereby, the difficulty level, realized payoffs differ between subjects who are assigned the easy and those who are assigned to hard mazes: women's payments are, on average, $6.63 €$; those who solve easy level mazes earned $10.45 €$ on average and women having solved hard level mazes earned 3.15 €. Men earned on average $7.68 €, 12.10 €$ for easy mazes, $3.84 €$ for hard level mazes. The gender gaps in payoffs are weakly significant (2-sided t-tests, at easy mazes: $\mathrm{t}=|1.857|, \mathrm{p}<0.07$, hard mazes: $\mathrm{t}=|1.913|$, $\mathrm{p}<0.06$ ). Women solved on average 7.13, men 8 mazes (2-sided t-test, $\mathrm{t}=|2.903|, \mathrm{p}<0.005) .215$ of women (217 of men) solved mazes of an easy difficulty level and 196 of them (188 of men) solved mazes of a hard difficulty level. Women with assigned easy mazes solved on average 9.91, and 4.41 with assigned hard mazes. Men who are assigned to easy mazes solved on average 11.26, men with hard mazes $4.977^{11}$ On average, women needed 25 minutes for the whole experiment;

\footnotetext{
${ }^{10}$ See Appendix $\mathrm{B}$ for an overview regarding the choice sets categorized in groups. For the present paper, we primarily deal with the choice sets that include competition against the mixed-gender group (choice set group 4) and the same-gender group (group 5). Additionally, we take into account the decisions subjects made in those choice sets that do not contain any competition against other participants, which therefore serve as a measure for a person's self-confidence (group 3).

${ }^{11}$ We deal with differences in payoffs as a consequence of the underlying choices as well as performance in the paper Beblo et al. (2017).
} 
men needed 26 minutes.

\section{Results}

We are interested in women's and men's competition preferences, in general, and in genderpairing preferences in competition. At first, we present a closer look at the individual competition behavior by choice sets' attributes and disclose gender-pairing effects for men and women separately. Second, we discuss potential drivers of the detected gender-pairing preferences 12 Third, we present an in-depth analysis of the gender gap in self-confidence and competition willingness.

\subsection{Gender-Pairing Effects in Competition Entry Behavior}

Competition is involved in eight of the 23 choice sets; four involving competition against a mixedgender group and the other four against a same-gender group ${ }^{13}$ Based on pooled choices in all competition-involving choice sets, $30.9 \%$ women and $31.6 \%$ men decided to compete (MannWhitney Test, MW, $\mathrm{z}=|0.505|, \mathrm{p}=0.614)$. From figure 1 it becomes clear that these numbers need more careful consideration: Almost $34 \%$ of women choose to compete when same-gender is indicated, i.e. a women only group, whereas only $27 \%$ of them do when gender is not specified. This contrast with men's competition behavior, who no matter the gender-mix of the opponents group compete by about $31 \%$.

Figure 1: Competition Entry Decisions on Average

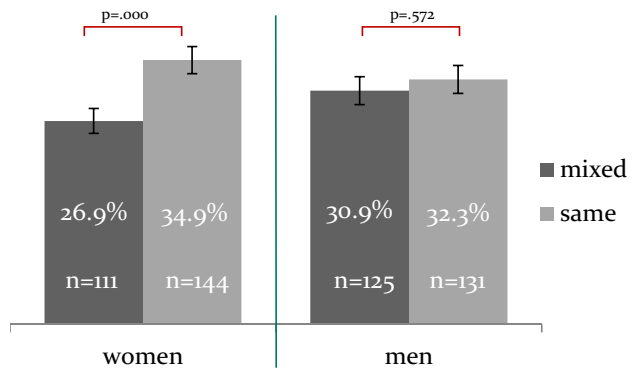

Note: Displayed are the mean values of competition choices and standard errors of the means by gender depending on the gender-mix of the competition group. P-values are from Wilcoxon signed-rank tests.

While the gender-pairing seems to have no impact on participating men's choice behavior, participating women are indeed affected. A Wilcoxon signed-rank test (WSR) rejects the null-

\footnotetext{
${ }^{12}$ Our analysis is based on a subset of all observations with the slowest one percent of female and male participants respectively being deleted. For this purpose, we calculated the actual ability distribution as the average time participants needed to solve the easy and hard level trial maze. We excluded female participants if their average time exceeds 714.5 seconds and male participants who took longer than 318 seconds. We also excluded subjects from the analysis who voted irrationally on choice set $\# 23$. Thus, we have a sample size of 414 women and 405 men. Table 8 in the Appendix C gives detailed information about the ability distributions.

${ }^{13}$ Relevant choice sets are taken from group 4 and 5 of all choice sets (see Appendix B and include choice sets $\# 11, \# 13, \# 14$, and \#16 when it is about mixed-gender competition and \#17, \#19, \#20, and \#22 when it is about same-gender competition. We omit choice sets $\# 12$, $\# 15$, \#18, and $\# 21$, which we only implemented to satisfy by design the preconditions of ensuring consistent and transitive individual preferences.

${ }^{14}$ We use non-parametric tests, as choice is not normally distributed. However, t-tests yield similar results.
} 
Figure 2: Competition Entry Decisions by Difficulty Level and Wage Spread

a) by Difficulty Level

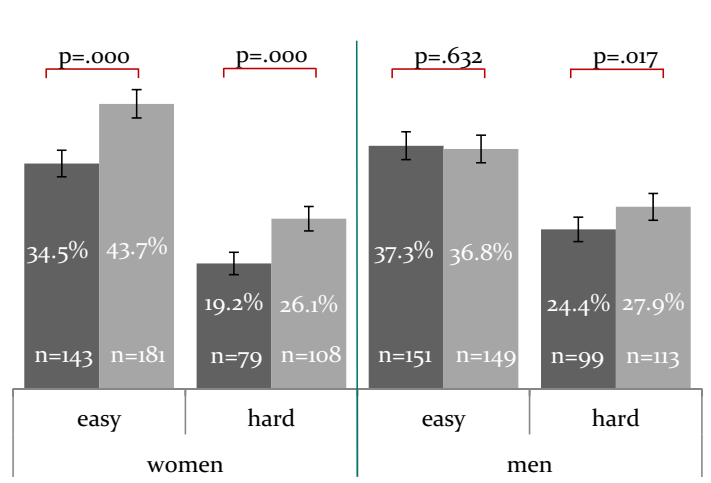

b) by Spread

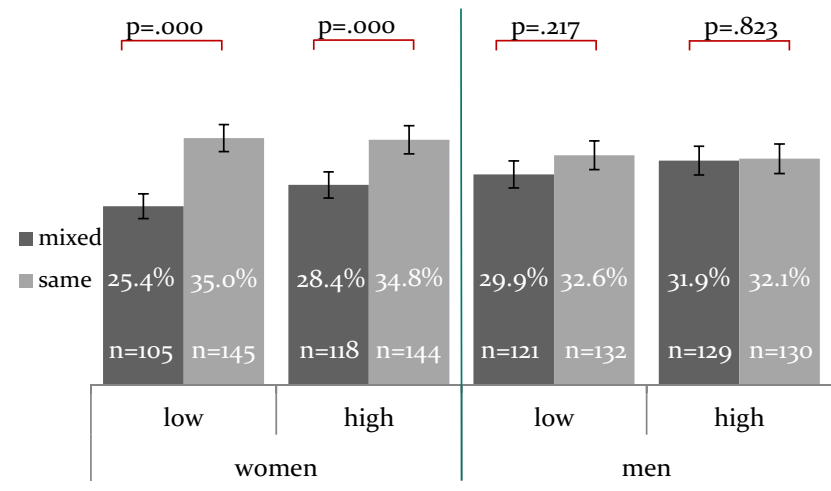

Note: Displayed are the mean values of competition entry choices and standard errors of the means by gender depending on the gender-mix of the competition group. Data average over choice sets at (a) the same difficulty level over both wage spread levels and (b) the same wage spread level over both difficulty levels. P-values are from Wilcoxon signed-rank tests.

hypothesis that the gender-pairing has no effect on women's willingness to compete: At that pooling level, we reject that choices are identically distributed at both levels of the gender$\operatorname{mix}(\mathrm{WSR},|\mathrm{z}|=5.360, \mathrm{p}<0.001$ ). In fact, women's competition willingness in a same-gender setting is on average 8 percentage points higher than if it is a mixed-gender setting. This suggests that our female participants prefer same-gender competition over competition against a mixed-gender group ${ }^{15}$ As regards the choice sets' attributes (See Figures $2 \mathrm{a}$ and $2 \mathrm{~b}$ ), women significantly prefer same-gender competition over mixed-gender competition at both difficulty levels (WSR, $|\mathrm{z}|=4.173,|\mathrm{z}|=4.556, \mathrm{p}<0.001$ ) as well as at both spread of wage levels (WSR, $|\mathrm{z}|=5.198,|\mathrm{z}|=3.570, \mathrm{p}<0.001)$. Regarding men's behavior, other than a significant effect at the hard difficulty level, we cannot detect any gender-mix related differences 16

Since participants decide repeatedly whether they would like to compete, we can track their choices at changing competition attributes and, hence, can focus on their choice sequences separately by the gender-mix. In figure 3, the leftmost data point \#4A represents the share of participants who never choose to compete in any of the competition-involving choice sets. The data points right to it depict the proportion of participants who choose to compete at least once (\#1B, \#2B, \#3B) up to always (\#4B). Surprisingly, nearly up to $50 \%$ of men never opt for competition $(\# 4 \mathrm{~A})$. While this share of men is stable with respect to the gender-mix, it differs significantly in the women sample: In a mixed-gender setting, slightly more than $51 \%$ of women are never willing to compete. Whereas in a same-gender competition setting only $41 \%$ of women are unwilling to compete; while a significantly larger share (58\%) are willing to compete at least once. In addition, WSR tests over all choice sequence groups reject that women's choice behavior is identically distributed at both levels of gender-mix and also among

\footnotetext{
${ }^{15}$ Wilcoxon signed-rank test on comparing same-gender and mixed-gender choices reveal for men $\mathrm{z}=|0.565|$, $\mathrm{p}=0.572$.

${ }^{16}$ We again perform Wilcoxon signed-rank tests that could not reject the null-hypothesis of a gender-mix effect in men's behavior neither at the easy difficulty level $(\mathrm{z}=|0.479|, \mathrm{p}=0.632)$ nor at both wage spread levels (low: $\mathrm{z}=|1.235|, \mathrm{p}=0.217$, high: $\mathrm{z}=|0.224|, \mathrm{p}=0.822)$. However, gender-mix at the hard difficulty level plays a minor role with slightly more men willing to compete against a same-gender group: WSR, $\mathrm{z}=|2.389|, \mathrm{p}<0.020$ ).
} 


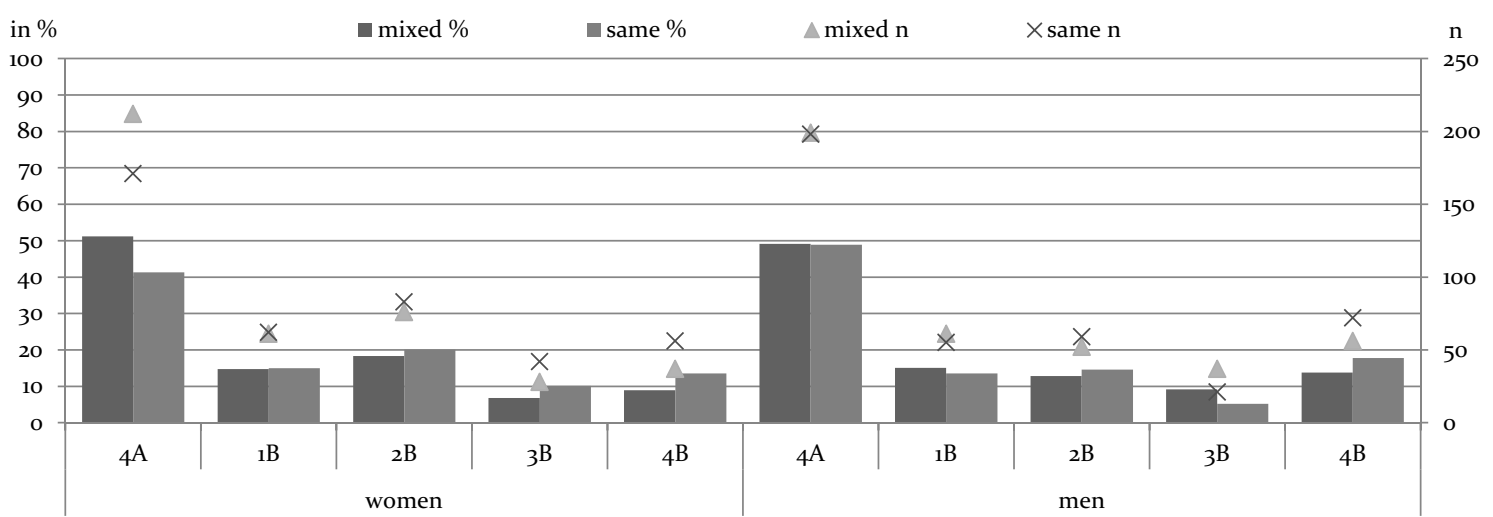

Note: Displayed are the shares (in \%, left y-axis) and absolute (n, right y-axis) values of women's and men's choice sequences in competition-involving choice sets separated by the gender-mix of the competition group. Sorting is from left to right with increasing competition willingness as the amount of option $\mathrm{B}$ choices increases. E.g. \#1B means that subjects chose Option B once and Option A three times. Bars sum up to $100 \%$ by gender and gender-mix.

those who compete at least once $(\# 1 \mathrm{~B})$ or always $(\# 4 \mathrm{~B}){ }^{17}$ We interpret this as evidence for women's greater willingness to compete, on average, if there is chance to compete against a group of women only. Although there are significant gender-mix effects for men who decide to compete at least three times, they are not consistent as they point in opposite directions 18

So far, nothing is said about the proportion of subjects who choose only one type of competition or even prefer competition in either gender-mix settings. How large is the share of people who go for same-gender competition but never choose mixed-gender competition? Figure 4 demonstrates overall choice behavior in all competition-involving choice sets. It discloses, from left to right, the proportion of people unwilling to compete (\#4A4A), willing to compete exclusively against a same-gender group (\#same-only), against both group constellations (\#mixed + same), exclusively against a mixed-gender group (\#mixed-only), or always (\#4B4B). While we find men's share to exceed that of women among those who always engage in competition (\#4B4B, MW, $\mathrm{z}=|2.614|, \mathrm{p}<0.01)$, the data reveal that women surpass men when it comes to an exclusively same-gender competition willingness: Indeed, $16 \%$ of women are exclusively willing to compete in a same-gender environment as opposed to only $9 \%$ of men (\#same-only, MW, $\mathrm{z}=|3.146|, \mathrm{p}<0.002)$. The group of women willing to compete from time to time, no matter the gender-mix, is weakly significantly bigger than that of men (\#same + mixed, MW, $\mathrm{z}=|1.711|$, $\mathrm{p}<0.100)$. Other choice sequence group do not differ significantly by gender.

What calls for further attention, is the fact that it is a same-gender competition setting that encourages women to compete - with our data pointing to a clear gender-pairing effect, which hold true only for women, but not for men.

\footnotetext{
${ }^{17}$ WSR tests yield for overall: $\mathrm{z}=|5.187|, \mathrm{p}<0.001$; for $\# 4 \mathrm{~A}: \mathrm{z}=|4.252|, \mathrm{p}<0.001$; for $\# 1 \mathrm{~B}: \mathrm{z}=|0.107|, \mathrm{p}=0.915$; for $\# 2 \mathrm{~B}: \mathrm{z}=|0.135|, \mathrm{p}=0.915$; for $\# 3 \mathrm{~B}: \mathrm{z}=|1.941|, \mathrm{p}<0.060$; for $\# 4 \mathrm{~B}: \mathrm{z}=|3.124|, \mathrm{p}<0.002$.

${ }^{18}$ WSR tests yield for overall: $\mathrm{z}=|0.441|, \mathrm{p}=0.660$; for $\# 4 \mathrm{~A}: \mathrm{z}=|0.119|, \mathrm{p}=0.906$; for \#1B: $\mathrm{z}=|0.655|, \mathrm{p}=0.513$; for \#2B: $\mathrm{z}=|0.480|, \mathrm{p}=0.631$; for $\# 3 \mathrm{~B}: \mathrm{z}=|2.530|, \mathrm{p}<0.020$; for $\# 4 \mathrm{~B}: \mathrm{z}=|2.921|, \mathrm{p}<0.005)$.
} 
Figure 4: Overall Competition Choice Sequences by Gender

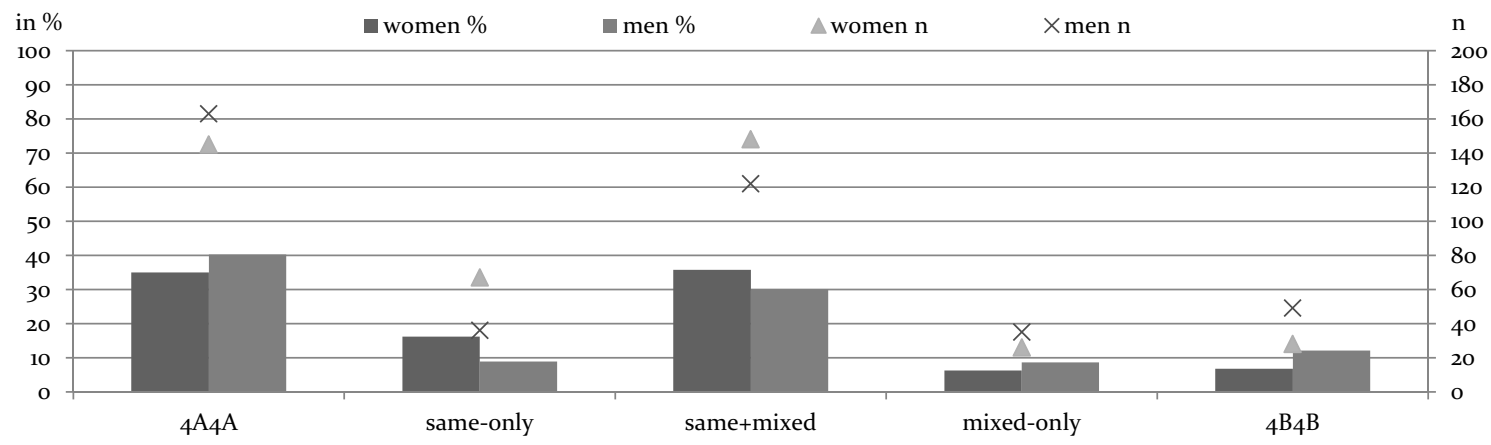

Note: Displayed are the shares (in \%, left y-axis) and absolute (n, right $\mathrm{y}$-axis) values of women's and men's overall choice sequences in competition-involving choice sets by gender. Sorting is from left to right with increasing competition willingness as the amount of option B choices increases with respect to the gender-mix. Bars sum up to $100 \%$ by gender.

\subsection{Determinants of Gender-Mix Effects}

Up to this point, we have shown that participating women's willingness to compete is depending on the gender-mix of the competition group. However, what drives these behavioral differences? What we have looked at so far, were the choices subjects made in those choice sets that involve competition. In this section, we investigate factors that might provide any explanatory power to solve that behavioral puzzle. We include personal ability in the task, self-confidence and over-confidence, as well as risk preferences. We use either revealed information stemming from the observed behavior in competition-free choice sets or stated information from the preexperimental questionnaire.

\subsubsection{Ability}

Since personal ability in solving a task might drive a person's willingness to compete, we use the actual individual performance time at the easy and hard level trial maze as a proxy for personal ability. By virtue of performing on a hard level and an easy level trial maze that are presented right at the beginning of the experiment, we make sure that subjects definitely know about their ability in this task. Unlike Datta Gupta et al. (2013, 824) who only assume "that the participants are aware of their own ability," we explicitly inform subjects about the absolute time they needed to solve each of the trial tasks. We infer that the longer a person needs to solve the task the worse their ability is and that this, in turn, negatively correlates with personal competition willingness. However, participants are not informed about their relative ability and thus can only guess others' ability by relying on personal beliefs. They can only perceive how good others are on the basis of all available information by the time they have to decide whether to enter a tournament or to avoid it. Table 8 in the Appendix C provides detailed information about the ability distributions at easy and hard level mazes.

The data reveal that ability and competition willingness are not correlated; neither for women (Spearman's $\rho=0.049, \mathrm{p}=0.318$ ) nor for men (Spearman's $p=-0.024, \mathrm{p}=0.625$ ) and also not when distinguishing between gender-mix. Figure 5 illustrates the cumulative distribution function of ability for those who are willing to compete separately by gender and the gender-mix of the 
Figure 5: Individual Ability of Competition Willing Subjects by Gender-Mix
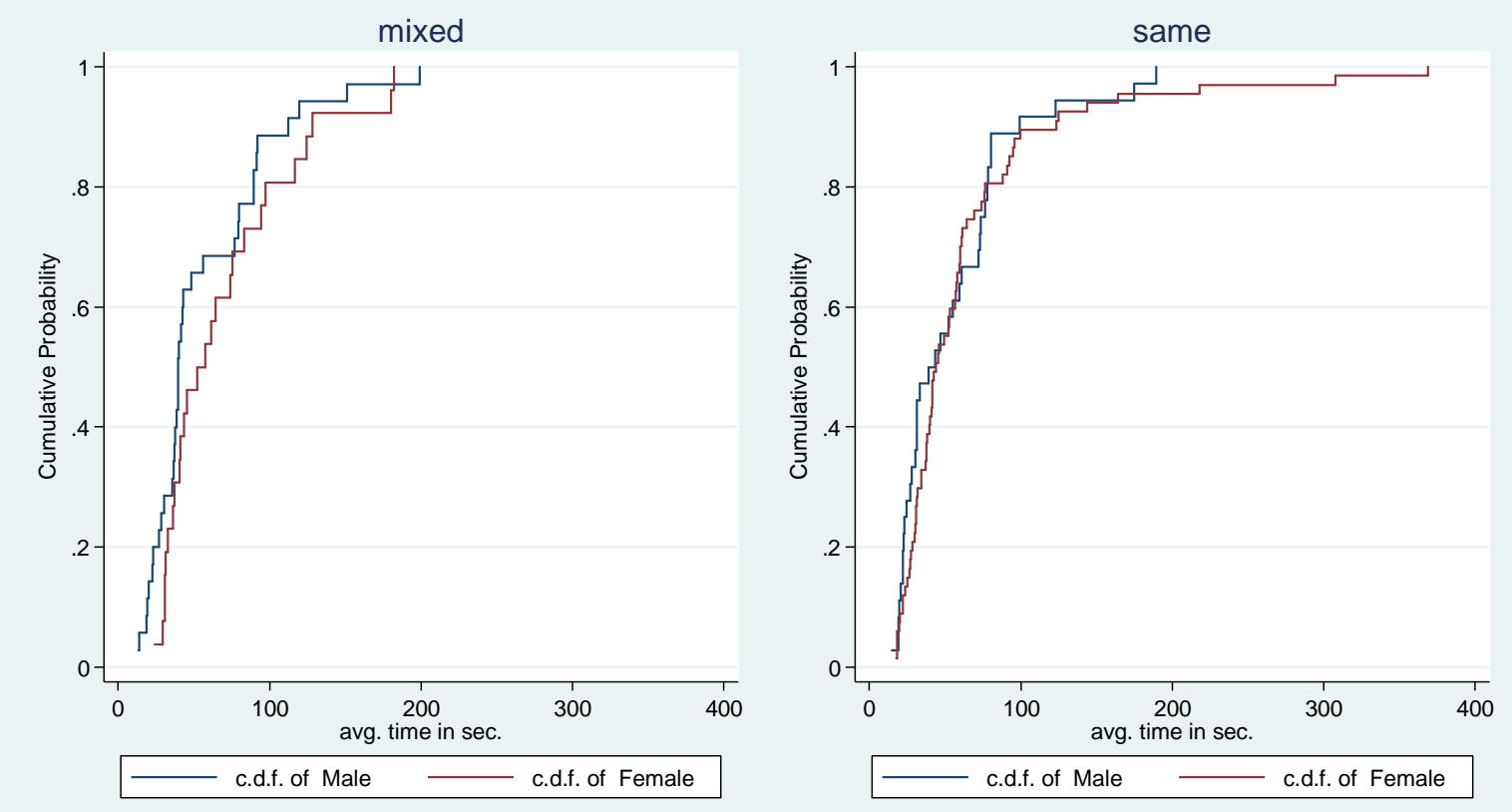

Note: Displayed are thecumulative distribution functions of the ability of those subjects who are willing to compete exclusively in mixed- resp. same-gender competition. Ability is measured by the average time subjects actually needed to solve the easy and hard level trial maze.

competition group. While we find a significant gender gap in the ability of all competition willing subjects (MW, $\mathrm{z}=|3.839|, \mathrm{p}<0.001$ ), it is no longer detectable among those who exclusively choose to compete against a mixed-gender group ( $\mathrm{MW}, \mathrm{z}=|1.524|, \mathrm{p}=0.128$ ) or exclusively against a same-gender group (MW, $\mathrm{z}=|0.685|, \mathrm{p}=0.494){ }^{19}$

\subsubsection{Self-confidence and Over-confidence}

As suggested in the literature (see i.a. Niederle \& Vesterlund, 2007; Nekby et al., 2008), it could be that self-confident women also have a high willingness to compete. Therefore, we expect to find at least a positive correlation between both, if not self-confidence to serve as a good predictor for competition willingness. Since making a decision is based on a personal assessment about one's own ability, our self-confidence measure refers to the concept of selfestimation (Moore \& Healy, 2008). Self-estimation is a measure that focuses solely on one's self-assessment of own absolute achievements or performance, which is also an expression for a subject's beliefs/self-assessment regarding own ability in performing this type of task. Therefore, we turn to information about an individual's behavioral choice in competition-free choice sets, i.e. choice sets that do not involve any competition with others, but mimicking competitioninvolving choice sets, recognizing the different levels of wage spread and difficulty involved ${ }^{20}$ Instead of competition against others, one might say that competition against oneself is involved

\footnotetext{
${ }^{19}$ Figure 14 in the Appendix contains the overall cumulative distribution functions for men and women.

${ }^{20}$ Choice sets $\# 5, \# 7, \# 8, \# 10$. See the detailed descriptions in Appendix A
} 
Figure 6: Single Option B Choices in Competition-free Choice Sets by Ability

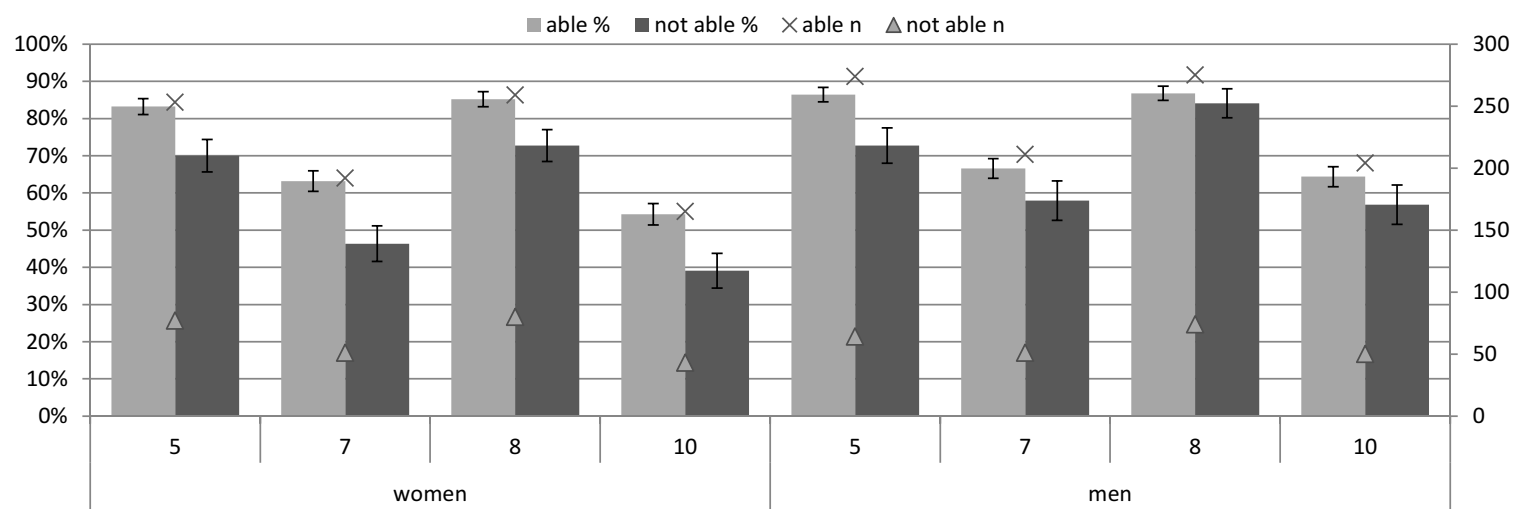

Note: Displayed are the shares (in \%, left y-axis) and absolute (n, right y-axis) values of participating women's and men's option $\mathrm{B}$ choices in each competition-free choice set $(\# 5, \# 7, \# 8, \# 10)$ depending on their actual ability to meet the involved threshold (able (left bars) vs. not able (right bars)). Overall, there are 304 able but 110 unable women and 317 able but 88 unable men.

in option $\mathrm{B}{ }^{21}$ Option $\mathrm{B}$, in a competition-free choice set, implements a threshold value of five mazes that has to be met in order to gain a higher and not a lower payment compared to having chosen option A. Thus, a rational decision requires the subject to correctly self-assess their own ability in performing this type of task, since being not able to meet the threshold would have the consequence of ending up with a lower piece rate wage than from having chosen the thresholdfree and, consequently, more secure option A or forgive the higher payment from option B if one is able to make it to the threshold. If a subject chooses option $\mathrm{B}$, she reveals herself to be a self-confident subject who believes they can meet the requirement. Hence, the more often a subject chooses option B, the stronger is her level of self-confidence regarding her own absolute ability, irrespective of being this choice correctly displaying her actual ability.

Since our measure for self-confidence is not only an indirect measure, but also incentive driven, it provides a good method to reveal a person's self-confidence by observing pure choice behavior. Figure 6 displays relative frequencies of option $\mathrm{B}$ choices in each of the competition-free choice sets distinguishing by the ability to meet the threshold. We explicitly address the correctness of subjects' self-confidence revealing choices: Since each subject knows their actual own absolute ability from the initial trial mazes, choices in competition-free choice sets also reveal overor even under-confidence if subjects deviate from personally optimal choices with respect to their own absolute ability. It appears that the same choice pattern as in competition-involving choice sets could be observed with respect to the difficulty level: In general, a hard difficulty level discourages participants to decide for option B $(\# 7, \# 10)$. Concerning gender differences, irrespective of subjects' ability, men pick option B significantly more frequently than women (MW, $\mathrm{z}=|3.189|, \mathrm{p}<0.002$ ), thereby exhibiting a higher level of self-confidence. The most severe difference could be detected when a hard difficulty level and a high spread of wage meet in choice set \#10 (MW, $\mathrm{z}=|3.597|, \mathrm{p}<0.001)$.

Figure 7 displays subjects' choice sequences in competition-free choice sets distinguishing by

\footnotetext{
${ }^{21}$ We interpret self-competition slightly different than Apicella et al. (forthcoming), who define it as the decision to compete against one's own previous performance. We instead aim at measuring the true self-estimation since each choice has payoff consequences.
} 
Figure 7: Choice Sequences in Competition-free Choice Sets by Ability

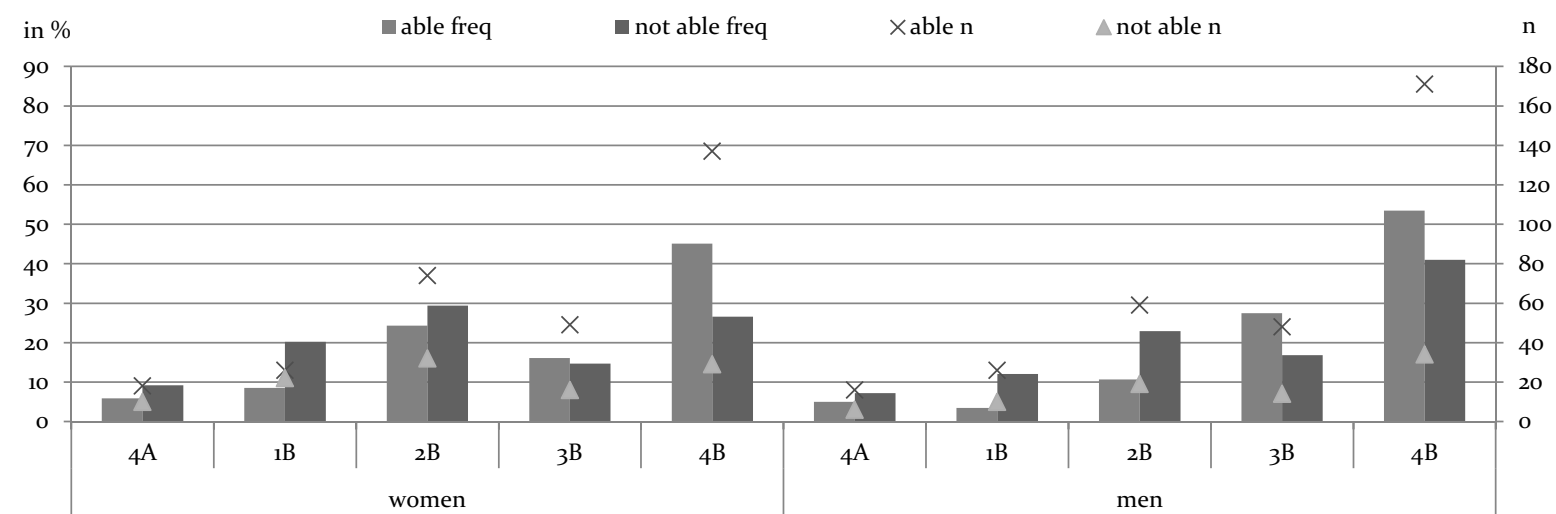

Note: Displayed are the shares (in \%, left y-axis) and absolute (n, right y-axis) values of participating women's and men's choice sequences in competition-free choice sets $(\# 5, \# 7, \# 8, \# 10)$ distinguishing by the actual ability to meet the involved threshold (able (left bars) vs. not able (right bars)). Sorting is from left to right with increasing self-confidence as the amount of option B choices increases. Bars sum up to $100 \%$ by gender and actual ability.

their ability to reach the threshold. Subjects not able to do so, ought to rarely, if ever, decide for option B, while able subjects should at least once decide for option B. We should, therefore, expect the bars to increase from left to right for those who are able and to decrease for those who are not. We assume that the more often a subject incorrectly decides between options A and $\mathrm{B}$, the more frequently she demonstrates wrong self-estimation, which in turn demonstrates the strength of a person's incorrect self-estimation.

The data reveal that at least the majority of able participants correctly reveal self-confidence: almost $45 \%$ of able women and $53 \%$ of able men correctly vote four times for option B (\#4B), as well as roughly $50 \%$ of women and $40 \%$ of men between one and three times $(\# 1 \mathrm{~B}, \# 2 \mathrm{~B}$, $\# 3 \mathrm{~B})$. However, among non-able participants we find more than a quarter of women, as well as more than $40 \%$ of men, opt for option B four times (\#4B), even though their actual and known ability to reach the threshold would suggest going for option A. We define these participants as over-confident. Under-confident subjects incorrectly voted for option A four times (\#4A) this included $6 \%$ of women and $5 \%$ of men.

Figure 8 links correctness of self-confidence to competition-entry behavior. It illustrates that the average competition entry rate of women who reveal themselves to be over-confident is much higher than that of the rest of the sample. The pattern is the same among women and men. Interestingly, a gender-mix effect is no longer present among the overconfident women sample (WSR, $\mathrm{z}=|0.798|, \mathrm{p}=0.425$ ). No matter the gender-pairing, over-confident women are more eager to compete than an economic rational would suggest when only the top $30 \%$ of the whole sample could gain from the highest piece-rate wage. A gender-mix effect is only present among women who correctly exhibit self-confident decisions (WSR, $\mathrm{z}=|5.313|, \mathrm{p}<0.001$ ) with a higher than rational proportion of them willing to compete in a same-gender environment.

\subsubsection{Risk-Taking Behavior}

In our pre-experimental questionnaire, we elicited subjects' risk attitudes from a self-reported 5 -item Likert scale on risk in general and in specific domains. We asked participants directly to 
Figure 8: Competition Entry Choices by Correctness of Self-Confidence

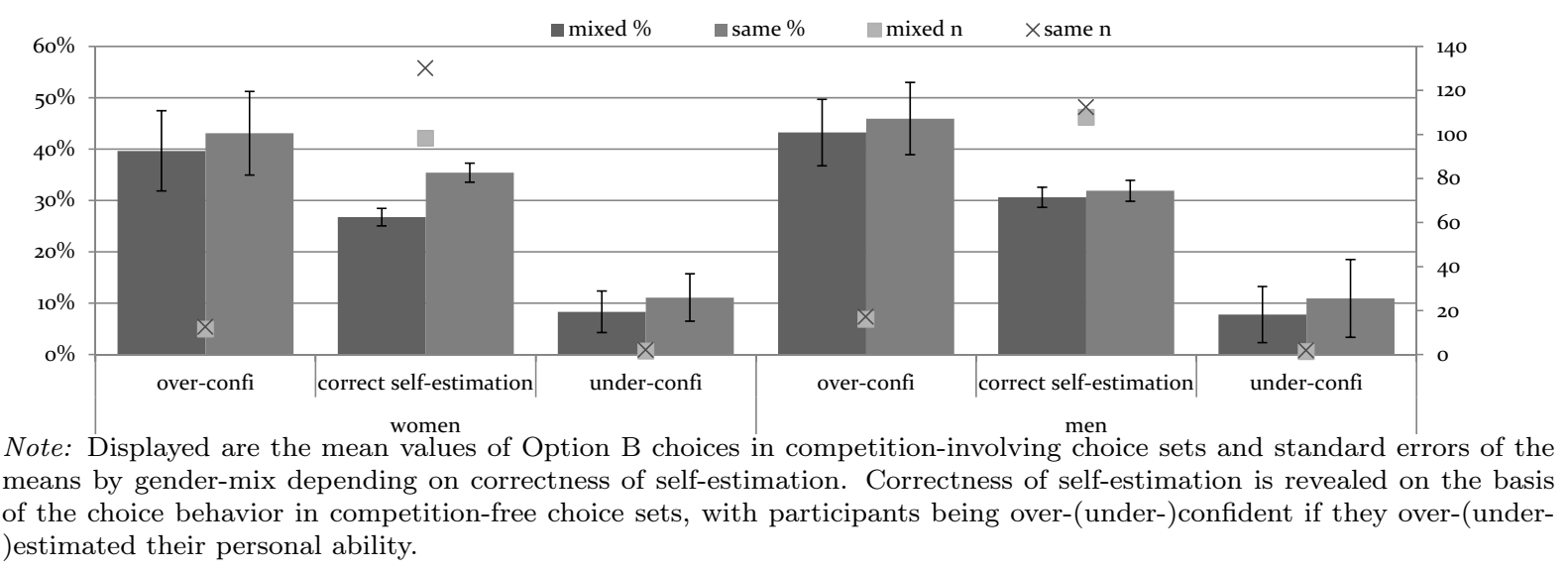

assess their personal willingness to take risk in general and in specific domains, as in money issues, when driving car, in their leisure time, and in their professional life. As in the German SocioEconomic Panel (SOEP), the question read, "How willing are you to take risks, in general (in money questions, in your leisure time, when driving car, in your professional life)?" Participants are required to answer each item on an eleven point scale from 0 to 10 , with 0 meaning not at all risk loving and 10 very much risk loving.

Our data reveal a substantial between-subjects heterogeneity in risk attitudes but also a significant gender gap in the willingness to take risk in general and in each domain, which is most substantial for money matters ${ }^{22}$ In line with other findings from self-reported risk attitudes (Dohmen et al., 2011), we also find our participating women to report a lower risk willingness than men do 23

Figure 9 links general risk-aversion and overall competition choice sequences graphically. Only for women do we detect a positive relationship, which is rather weak. However, we find women who never decide for mixed-gender competition $(\# 4 \mathrm{~A})$ to be significantly less risk-loving than women who always decide for mixed-gender competition (\#4B)(MW, $\mathrm{z}=|2.393|, \mathrm{p}<0.020$ ). There is no difference in risk willingness among same-gender competition willing women (MW, $\mathrm{z}=|1.377|, \mathrm{p}=0.169)$. For men we cannot find such a pattern.

\subsubsection{Econometric Evidence on Determinants of Gender Pairing}

Since the gender-mix of the competitors group is only relevant for women, we restrict our sample in the following to the women subgroup ${ }^{24} \mathrm{We}$ account for the fact that the choices subjects make might be interrelated over choice sets and we also account for the influence of socio-economic factors. Since subjects make decisions on eight subsequent sets of choices that all specify competition in Option B, we can treat the data set as a panel and account for individual heterogeneity.

\footnotetext{
${ }^{22}$ Figure 12 in Appendix C presents the cumulative distribution functions. Detailed data on stated risk willingness in each domain are available from the authors upon request.

${ }^{23}$ We used an ex-ante administered risk measure as opposed to Lönnqvist et al. $(2015)$ who do not find gender differences.

${ }^{24}$ Estimation results for men are presented in Table 7 in the Appendix C
} 


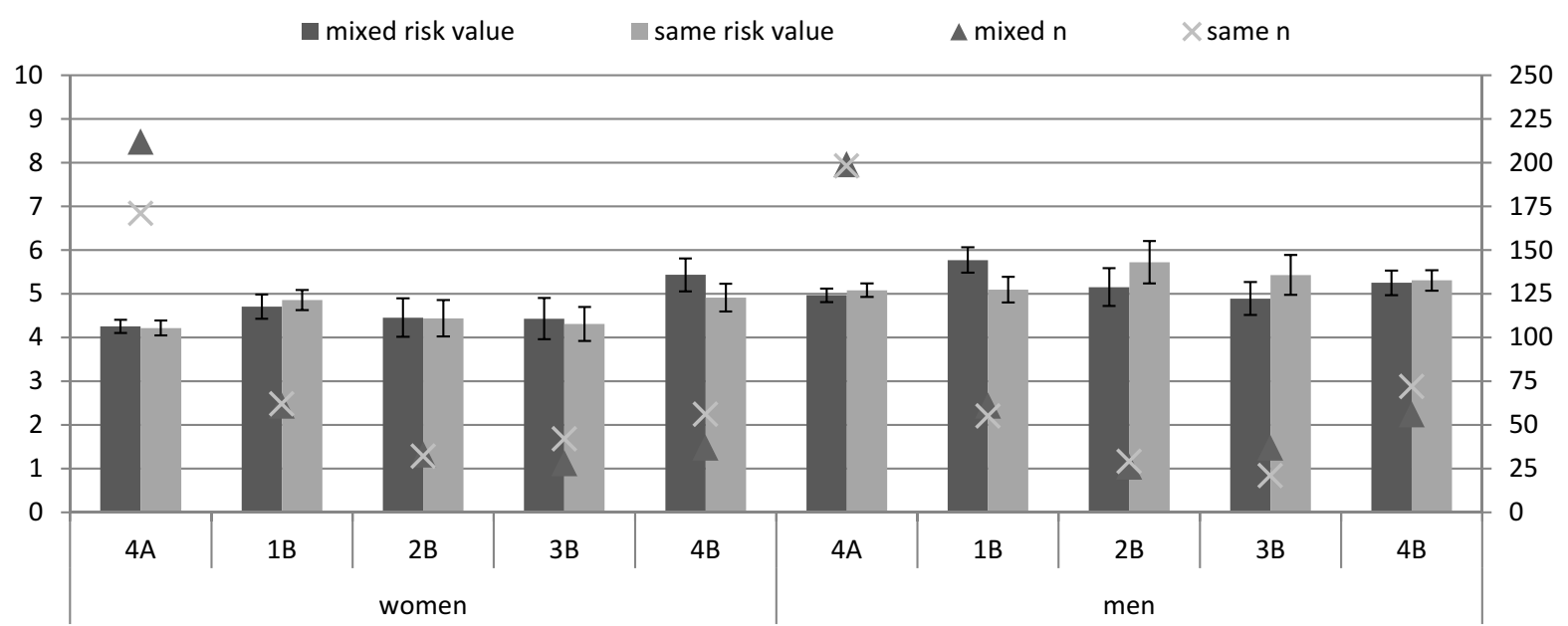

Note: Displayed are the mean self-reported risk values (left axis) of participants by choice sequence and gender-mix of the competition group plus the standard errors of the means as well as the total .

Table 1 reports average marginal effects on participating women's decision to compete from several logistic panel regressions using population averaged specifications controlling for socioeconomic influences. While model (1) estimates the pure effect of gender-pairing (same-gender, a dummy variable: 1 if the competitors group is of the same gender, 0 applies to mixed-gender), model (2) analyzes the influence of the other attributes: the spread of the wage vector (spread, a dummy variable: 1 if the spread is high, 0 low) and the difficulty level (diffi, a dummy variable: 1 if difficulty is hard, 0 easy).

At first glance, the strong and robust effect of a same-gender setting on women's decision to enter competition is evident. The first row confirms that the average marginal effect of a samegender group is substantially positive and highly significant for the participating women across all model specifications. It indicates a substantial increase in the probability of an average woman to choose to compete if the group of competitors is a group of women only, as opposed to a mixed-gender group, by about 8 percentage points. This is quite a large behavioral effect that calls for further attention, particularly since none of the choice sets' attributes explains the strong effect of a same-gender setting 25 Nonetheless, as Table 2 summarizes, recognizing the interactions of the choice sets' attributes difficulty and wage spread is required, as same-gender effects competition willingness differently, depending on the combination.

$<<<<$ Table 1 to insert here. $>>>>$

Therefore, we incorporate additional potential mechanisms in our models: model (3) personal ability, which is continuous and increasing in the time a person needed to solve the hard level trial maze; then model (5) includes the variable self-confi, which is a dummy and built as an interaction variable of the choices in each of the four competition-free choice sets (choice sets $\# 5, \# 7, \# 8, \# 10)$ with 1 displaying "having chosen Option B in each of the choice sets

\footnotetext{
${ }^{25}$ We replicate this analysis for the men subsample and find, once again, that a gender-mix effect is almost absent (See Table 7 in the Appendix C).
} 


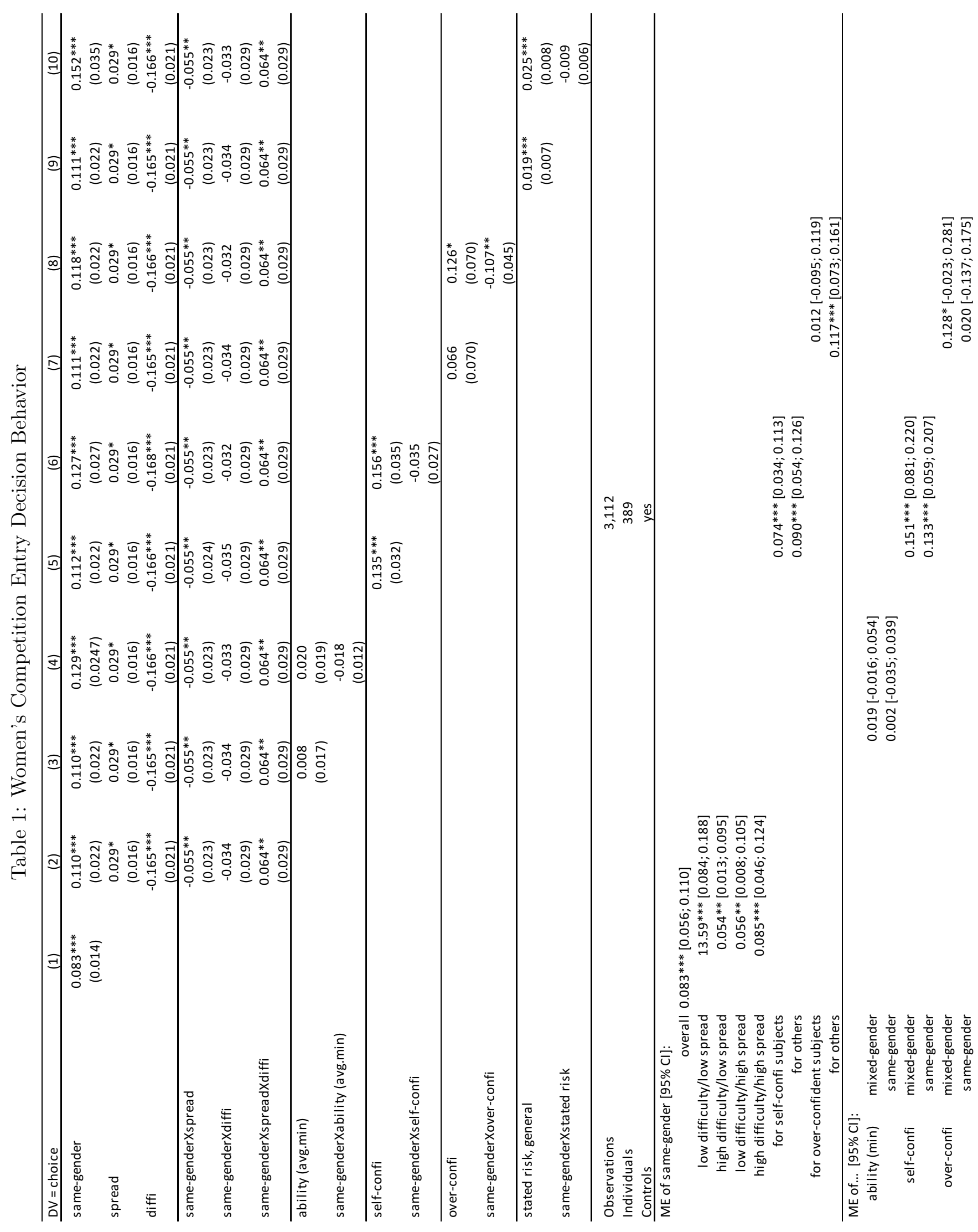

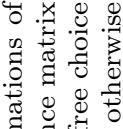

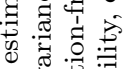

둥

过

㺃.

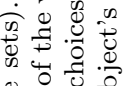

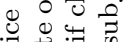

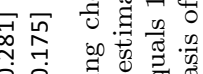

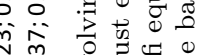

온

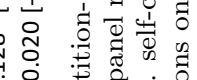

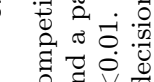

$\infty$ 证

원

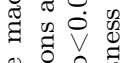

䂧类

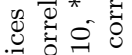

讨 (*)

过震

o

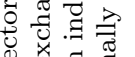

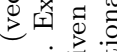

茟

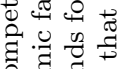

8 응 흥 뭉

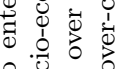

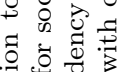

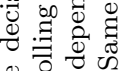

考

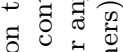

on

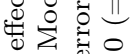

a. 0 을 마의 政政

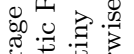

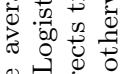

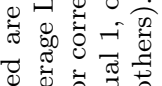
잉

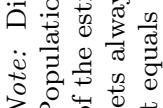


Table 2: Same-gender Effect at Different Combinations of Difficulty and Spread Levels

\begin{tabular}{ccccc}
\hline & \multicolumn{3}{c}{ Spread } & \multirow{2}{*}{ Difference } \\
\cline { 2 - 4 } & low & high & \\
\hline \multirow{2}{*}{ Difficulty } & easy & $13.6 \%$ & $5.6 \%$ & Chi2 $=6.53, \mathrm{p}=0.011$ \\
\cline { 2 - 4 } & hard & $5.4 \%$ & $8.5 \%$ & Chi2 $=1.33, \mathrm{p}=0.249$ \\
\hline \multicolumn{2}{c}{ Difference } & Chi2 $=6.45, \mathrm{p}=0.011$ & Chi2 $=0.87, \mathrm{p}=0.352$ & \\
\hline
\end{tabular}

Note: Displayed are average marginal effects on the decision to enter competition (vector of (0-1) at the different combinations of difficulty and spread levels and respective Wald Chi tests results. Base is the regression model 2 of Table 1

no matter the spread and difficulty level involved". This could be interpreted as strong selfconfidence with respect to one's own ability to solve this type of task, but it does not consider the correctness of that expressed self-confidence. Thus, model (7) adds a slight correction to model (5) by recognizing whether subjects had correctly decide for Option B as an indicator for over-confidence: over_confi is a dummy variable and calculated on the basis of the actual ability to meet the threshold in competition-free choice sets derived from the time a subject needed at the hard level trial maze ( 1 if Option $B$ in competition-free choice sets $(\# 5, \# 7$, $\# 8, \# 10)$ is chosen although the threshold would have not been met based on the trial maze performance, 0 otherwise). Model (9) integrates individual's stated risk willingness from the pre-experimental questionnaire and describes the individual general risk score; it increases the more the participant is willing to take risk.

Apparently, ability and self-confidence do not explain any of an average woman's decision to engage in same-gender competition. However, self-confidence has a strong effect on the decision to enter competition in general. So to say: If an average woman votes for Option B in each of the competition-free choice sets, thereby revealing herself to be self-confident, since she evaluates her own absolute ability to be good enough to meet the option's requirements, then she is substantially more likely to engage in competition - a situation that naturally involves a relative self-assessment - self-assessing own ability relatively to others'. Thus, self-confidence works as a dominant determinant of women's competition willingness in general. On average, it boosts women's competition entry decisions no matter the gender-mix by more than 10 percentage points. However, it does not provide any additional explanation of women's strong preferences for same-gender competition.

By contrast, over-confidence does provide explanation, as its interaction with same-gender is substantially significant and, in reverse magnitude, as big as the coefficient of same-gender. Its negative sign suggests that a same-gender effect is reduced for an average, but over-confident, woman with the consequence that gender-pairing would no longer be crucial for her decision to compete. Indeed, as proven by a Wald-test, the average marginal effect of same-gender is different for over-confident women compared to the remaining women $\left(\chi^{2}(1)=4.20, p<.040\right){ }^{26}$ The bottom line is that our over-confident women in the sample are, particularly in a mixedgender environment, significantly more willing to compete than women who correctly or even

\footnotetext{
${ }^{26}$ Contrary to that, there is almost no difference in the same-gender effect for men conditioned on overconfidence $\left(\chi^{2}(1)=0.13, p<.715\right)$.
} 
under-estimate own abilities. The model predicts that about $42 \%$ of them compete against a mixed-gender group, which is significantly different to the $25 \%$ of those women being identified as not over-confident $\left(\chi^{2}(1)=4.17, p<.050\right)$. Hence, the gap in competition willingness between mixed- and same-gender settings diminishes.

As regards the fourth mechanism, risk-willingness, we confirm its relevance for competition willingness itself: The more risk-loving an average women is the more likely they are to compete in general. However, it does not provide additional explanatory power for women's decision to engage in same-gender competition. Figure 10 captures the heterogeneity of the same-gender marginal effect on the decision to enter a tournament along the risk willingness scale. The effect is more pronounced for those women who self-report to be not at all or only a little risk-loving and vanishes with increasing willingness to take risk. Thus. the gender-mix apparently does not make a difference for women who are more risk loving on average. There is also no effect for men, no matter where they are on the risk scale.

Figure 10: Average Marginal Effect of Same-gender on Competition Entry Decisions Depending by Individual Risk Score

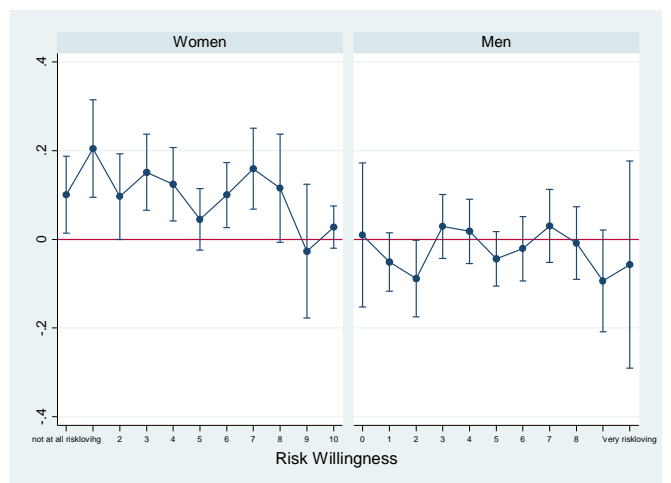

Note: Displayed are average marginal effects of a same-gender setting on the decision to enter competition (vector of (0-1) within $95 \%$ confidence intervals depending on the level self-reported risk-willingness. Bases is Model (10) of Table 1 and 7 (in Appendix C.

\subsection{Gender-Mix Effects Within the Full-Time Employed Women Subsample}

In the following, we test whether our findings are also true for full-time employed women since our data on full-time employed women aged 25 to 51 is comparable to the respective subsample of the German population, surveyed in the SOEP, regarding income, education and risk-willingness (See Table 9 in Appendix C). Our analysis presents multivariate results on that restricted sample. Estimation results from panel logistic regression models, conducted as before are displayed in Table 11 in the Appendix C. The models confirm our previous findings and present evidence for the same-gender environment to boost women's competition willingness. This is particularly important since the restricted sample also stands for greater generalizability and higher external validity of our findings. Thus we can draw much stronger empirical conclusions about women's competition willingness and their preferences for same-gender competitors.

Concerning the mechanisms that potentially drive same-gender competition preferences, we confirm our previous findings, as there is no evidence for ability or self-confidence to have an addi- 
tional explanatory effect. What we do find is a significant, but small, negative relationship to risk-willingness. However, this effect is much more pronounced compared to the total women sample meaning that with increasing risk-lovingness, the full-time employed women are slightly less prone to prefer same-gender over mixed-gender competition. Apparently, it seems that a gender-mix effect is increasingly negligible the more risk-loving an average women is ${ }^{27}$ This effect is not present among the part-time employed women in our sample (see also Figure 16 in the Appendix C).

Similarly, we do find a stronger effect of being over-confident in the full-time employed women sample, but not in the part-time women sampl (See Table 12 in the Appendix C)e. Competition willingness among the over-confident women who work full-time does not, as in the whole sample, depend on the gender-mix of the competitors group: The model predicts that about $51 \%$ of them compete against a mixed-gender group, which is significantly different to only $22 \%$ women who are identified as not over-confident $\left(\chi^{2}(1)=6.27, p<.020\right)$.

\subsection{An Addendum to the Gender Gap in Competition Willingness}

This section serves to discuss the gender gap in competition. First of all, we present an econometric check of the gender gap in competition willingness with and without controlling for socio-economic characteristics. We then explore the gender gap in self-confidence and come back to showing how the gender gap in competition willingness relates to this.

We perform several population average logistic panel regressions to investigate group-specific effects in the decision to engage in competition based on the eight choice sets involving competition. Table 3 reports estimation results regarding a gender gap in competition willingness for which we regressed the decision to enter competition (a dummy variable: 1 if choice is option $\mathrm{B}, 0$ otherwise) on $(1+2)$ gender (female, a dummy variable: 1 if subjects are female, 0 male) and on $(3+4)$ the gender-mix of the competitors group (same-gender, a dummy variable: 1 if it is of the same gender, 0 applies to mixed-gender) plus $(5+6)$ interactions to allow for a different impact of the gender-mix by gender.

$$
<<<<\text { Table } 3 \text { to insert here. }>>>>
$$

Unlike what other studies find, the first columns point to a non-significant gender gap in the general competition willingness. However, as column (5) demonstrates with the interaction of female and same-gender, we confirm that a same-gender competition environment only makes a difference for women (Wald Chi2 $(1)=36.43$, $\mathrm{p}<0.001$ vs. Wald Chi2 $(1)=0.73, \mathrm{p}=0.392$ ). That is, women are by almost 8 percentage points significantly more likely to compete against other women than against a group of women plus men ${ }^{28}$ Once acknowledging that the gender-mix of the competitors group might play a role, the data additionally reveal a conditional gender gap that increases substantially to roughly 7 percentage points in a mixed-gender environment when controlling for socio-economic characteristics (column 6) and increases in significance, while still

\footnotetext{
${ }^{27}$ See further descriptive statistics in Table 10 in the Appendix $\mathrm{C}$

${ }^{28}$ The same-gender effect is significantly different for women and men (Wald Chi2 $(1)=15.52, \mathrm{p}<0.001$ ).
} 
Table 3: Gender Gap in Competition Choices

\begin{tabular}{|c|c|c|c|c|c|c|}
\hline $\mathrm{DV}=$ choice & (1) & $(2)$ & (3) & (4) & (5) & (6) \\
\hline \multirow[t]{2}{*}{ female } & -0.009 & -0.032 & -0.004 & -0.027 & $-0.047^{*}$ & $-0.071^{* *}$ \\
\hline & $(0.025)$ & $(0.026)$ & $(0.025)$ & $(0.026)$ & $(0.027)$ & $(0.028)$ \\
\hline same-gender & & & $(0.009)$ & $(0.009)$ & $(0.012)$ & $(0.012)$ \\
\hline \multirow[t]{2}{*}{ femaleXsame-gender } & & & & & $0.073^{* * *}$ & $0.073^{* * *}$ \\
\hline & & & & & $(0.018)$ & $(0.018)$ \\
\hline Individuals & & & & 768 & & \\
\hline Controls & no & yes & no & yes & no & yes \\
\hline \multicolumn{7}{|l|}{ ME of same-gender $[95 \% \mathrm{Cl}]:$} \\
\hline for women & & & & & $0.083^{* * *}[0.056 ; 0.110]$ & $0.083^{* * *}[0.056 ; 0.110]$ \\
\hline for men & & & & & $0.011[-0.014 ; 0.035]$ & $0.011[-0.014 ; 0.035]$ \\
\hline
\end{tabular}

Note: Displayed are average marginal effects on the decision to enter competition (vector of (0-1) choices made in 8 competition-involving choice sets). Bases are estimations of Population-Average Logistic Regression Models controlling for socio-economic factors. Exchangeable error correlations are used and a panel robust estimate of the variance-covariance matrix of the estimator corrects tiny standard errors for any dependency over rounds for a given individual. $*$ p $<0.10, * *$ $\mathrm{p}<0.05, * * * \mathrm{p}<0.01$.

no gender gap emerges in a same-gender setting 29 Thus, it turns out that women and men behave more or less similarly if their opponents have the same gender and women's commonly perceived reluctance toward competition only applies to competition in mixed-gender settings.

In line with most of the literature, we also find a substantive and significant gender gap in self-confidence revealing choices, with women being less prone to making self-confident decisions (See Table 4). Ability does not explain this gap. We find ability only affects men's choices in such a way that it even lessens the gender gap in self-confidence. It could be that this relates to the finding that ability is not significant in explaining women's competition willingness, as demonstrated in Section 4.2.4,

$<<<<$ Table 4 to insert here. $>>>>$

Since the gap in self-confidence is substantial, it might provide insight for explaining the gap in mixed-gender competition-entry decisions (see table 5). However, it appears that controlling for the interaction of self-confidence and female (Model 6) results in the coefficient of female becoming insignificant. This means that self-confidence is not only a matter of fact for women's (see again table 1) but also for men's competition willingness. Consequently, the gender gap in self-confidence explains the gender gap in mixed-gender competition among the self-confident subjects away (Model 8). This is very similar with over-confidence: If there is mixed-gender competition, it appears that no gender gap in competition willingness exists among over-confident subjects (Model 10). Ability does not provide an explanation.

\section{$<<<<$ Table 5 to insert here. $>>>>$}

\footnotetext{
${ }^{29}$ The gender gap under mixed-gender competition is significantly different from that under same-gender (Wald Chi2(1) $=14.68, \mathrm{p}<0.001)$.
} 
Table 4: Gender Gap in Self-Confidence

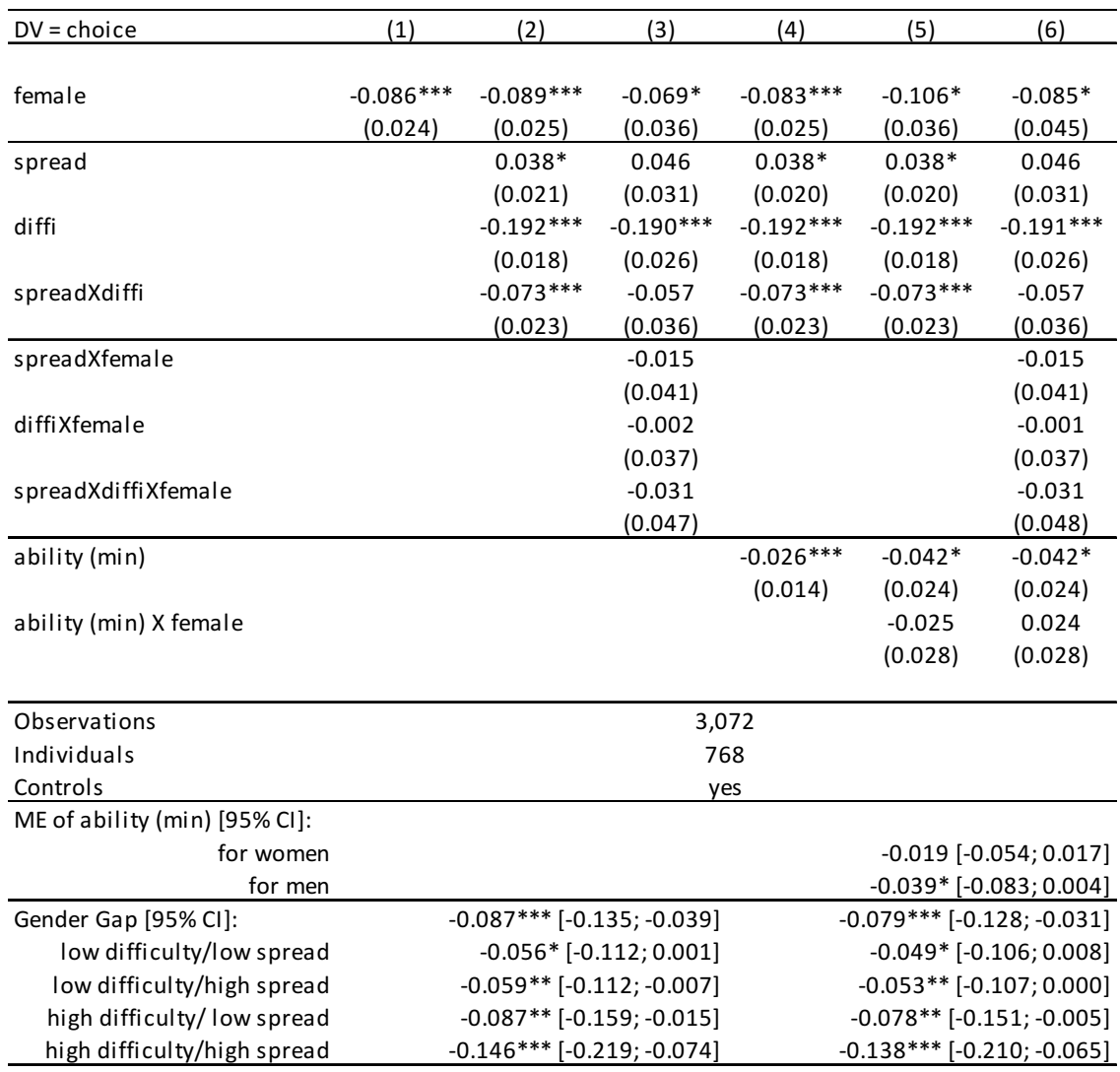

Note: Displayed are average marginal effects on the decision to vote for Option B in competition-free choice sets (vector of (0-1) choices made in choice sets $\# 5, \# 7, \# 8, \# 10)$. Bases are estimations of Population-Average Logistic Regression Models controlling for socio-economic factors. Exchangeable error correlations are used and a panel robust estimate of the variance-covariance matrix of the estimator corrects tiny standard errors for any dependency over rounds for a given individual. * $\mathrm{p}<0.10, * * \mathrm{p}<0.05$, *** $\mathrm{p}<0.01$.

\section{Discussion and Conclusions}

Our experiment contributes to the rapidly growing literature on competition willingness. We confirm gender-pairing effects on women's decisions to select into competition and provide strong evidence that women are more willing to engage in competition if their competitors are also women. We also provide evidence on the fact that in a same-gender environment the widely documented gender gap in competition is closed - while a gap in a mixed-gender competition setting remains. However, there is no such gender gap among the self-confident, not to speak among the over-confident participants. This is related to the question why women prefer samegender competition: we find gender-mix effects only among women who correctly or even underestimate their own achievements: They restrain from mixed-gender competition but are very eager when it comes to same-gender competition. Contrary to that, women who over-estimate their achievements but want to compete either way (we classify them as being over-confident) do not hinge their decision on the gender-mix of the competitors group. Our results therefore highlight that women's commonly perceived reluctance toward competition does not apply to competition in every situation.

Other mechanisms that are discussed in the literature for why women shy away from competition 
Table 5: Gender Gap in Competition Entry Behavior Controlling for Ability, Self-Confidence and Over-confidence

\begin{tabular}{|c|c|c|c|c|c|c|c|c|c|c|c|}
\hline DV = choice & (1) & (2) & (4) & (5) & (6) & (7) & (8) & (9) & (10) & (11) & (12) \\
\hline female & $\begin{array}{c}-0.0746^{* * *} \\
(0.0284)\end{array}$ & $\begin{array}{c}-0.0856^{* *} \\
(0.0408)\end{array}$ & $\begin{array}{c}-0.0948^{* *} \\
(0.0420)\end{array}$ & $\begin{array}{l}-0.0487^{*} \\
(0.0278)\end{array}$ & $\begin{array}{l}-0.0470 \\
(0.0323)\end{array}$ & $\begin{array}{l}-0.0480^{*} \\
(0.0278)\end{array}$ & $\begin{array}{l}-0.0651^{*} \\
(0.0347)\end{array}$ & $\begin{array}{c}-0.0665^{* *} \\
(0.0279)\end{array}$ & $\begin{array}{c}-0.0641^{* *} \\
(0.0286)\end{array}$ & $\begin{array}{c}-0.0658^{* *} \\
(0.0280)\end{array}$ & $\begin{array}{c}-0.0689^{* *} \\
(0.0288)\end{array}$ \\
\hline same-gender & $\begin{array}{c}0.0104 \\
(0.0122)\end{array}$ & $\begin{array}{c}0.0104 \\
(0.0122)\end{array}$ & $\begin{array}{c}0.0152 \\
(0.0173)\end{array}$ & $\begin{array}{c}0.0104 \\
(0.0122)\end{array}$ & $\begin{array}{c}0.0104 \\
(0.0122)\end{array}$ & $\begin{array}{c}0.0175 \\
(0.0174)\end{array}$ & $\begin{array}{l}0.00155 \\
(0.0210)\end{array}$ & $\begin{array}{c}0.0104 \\
(0.0122)\end{array}$ & $\begin{array}{c}0.0104 \\
(0.0122)\end{array}$ & $\begin{array}{l}0.0158 \\
(0.0126)\end{array}$ & $\begin{array}{c}0.0115 \\
(0.0129)\end{array}$ \\
\hline femaleXsame-gender & $\begin{array}{c}0.0734^{* * *} \\
(0.0184) \\
\end{array}$ & $\begin{array}{c}0.0735^{* * *} \\
(0.0184) \\
\end{array}$ & $\begin{array}{c}0.0879 * * * \\
(0.0249) \\
\end{array}$ & $\begin{array}{c}0.0736 * * * \\
(0.0184) \\
\end{array}$ & $\begin{array}{c}0.0736^{* * *} \\
(0.0184) \\
\end{array}$ & $\begin{array}{c}0.0723^{* * *} \\
(0.0185) \\
\end{array}$ & $\begin{array}{l}0.101^{* * *} \\
(0.0298) \\
\end{array}$ & $\begin{array}{c}0.0733^{* * *} \\
(0.0184) \\
\end{array}$ & $\begin{array}{c}0.0732^{* * *} \\
(0.0184) \\
\end{array}$ & $\begin{array}{c}0.0722 * * * \\
(0.0184) \\
\end{array}$ & $\begin{array}{c}0.0806 * * * \\
(0.0193) \\
\end{array}$ \\
\hline $\begin{array}{l}\text { ability (avg.min) } \\
\text { ability X female }\end{array}$ & $\begin{array}{c}0.0156 \\
(0.0151)\end{array}$ & $\begin{array}{c}0.00731 \\
(0.0282) \\
0.0122 \\
(0.0318) \\
\end{array}$ & $\begin{array}{c}0.0106 \\
(0.0287) \\
0.0199 \\
(0.0332) \\
\end{array}$ & & & & & & & & \\
\hline $\begin{array}{l}\text { same-genderXability (avg.min) } \\
\text { same-genderXability X female }\end{array}$ & & & $\begin{array}{l}-0.00588 \\
(0.0156) \\
-0.0124 \\
(0.0194) \\
\end{array}$ & & & & & & & & \\
\hline $\begin{array}{l}\text { self-confi } \\
\text { self-confi } X \text { female }\end{array}$ & & & & $\begin{array}{l}0.155^{* * *} \\
(0.0235)\end{array}$ & $\begin{array}{l}0.157^{* * *} \\
(0.0346) \\
-0.00317 \\
(0.0472) \\
\end{array}$ & $\begin{array}{l}0.162^{* * * *} \\
(0.0255)\end{array}$ & $\begin{array}{c}0.149 * * * \\
(0.0365) \\
0.0299 \\
(0.0510) \\
\end{array}$ & & & & \\
\hline $\begin{array}{l}\text { same-gender X self-confi } \\
\text { same-gender } X \text { self-confi X female }\end{array}$ & & & & & & $\begin{array}{l}-0.0123 \\
(0.0187)\end{array}$ & $\begin{array}{c}0.0152 \\
(0.0255) \\
-0.0549 \\
(0.0375) \\
\end{array}$ & & & & \\
\hline $\begin{array}{l}\text { over-confi } \\
\text { over-confi X female }\end{array}$ & & & & & & & & $\begin{array}{l}0.106^{* *} \\
(0.0469)\end{array}$ & $\begin{array}{l}0.119 * * \\
(0.0604) \\
-0.0290 \\
(0.0961) \\
\end{array}$ & $\begin{array}{l}0.136^{* * *} \\
(0.0483)\end{array}$ & $\begin{array}{c}0.125^{* *} \\
(0.0613) \\
0.0272 \\
(0.0989) \\
\end{array}$ \\
\hline $\begin{array}{l}\text { same-gender } X \text { over-confi } \\
\text { same-gender } X \text { over-confi } X \text { female }\end{array}$ & & & & & & & & & & $\begin{array}{r}-0.0554^{*} \\
(0.0305)\end{array}$ & $\begin{array}{l}-0.0115 \\
(0.0395) \\
-0.0972 \\
(0.0603) \\
\end{array}$ \\
\hline $\begin{array}{l}\text { Observations } \\
\text { Individuals } \\
\text { Controls }\end{array}$ & & & & & & $\begin{array}{c}6,144 \\
768 \\
\text { yes }\end{array}$ & & & & & \\
\hline $\begin{array}{cc}\text { Gender Gap }[95 \% \mathrm{Cl}]: & \begin{array}{r}\text { mixed-gender } \\
\text { same-gender }\end{array} \\
\end{array}$ & $\begin{array}{r}-0.030 \\
-0.065^{* *} \\
0.005 \\
\end{array}$ & $\begin{array}{l}0.082 ; 0.023] \\
.119 ;-0.012] \\
0.052 ; 0.063]\end{array}$ & & & & $\begin{array}{r}-0.011 \\
-0.047^{*} \\
0.024 \\
\end{array}$ & $\begin{array}{l}.062 ; 0.040] \\
.099 ; 0.005] \\
.032 ; 0.080]\end{array}$ & & & $\begin{array}{r}-0.025 \\
-0.064^{* *} \\
0.006 \\
\end{array}$ & $\begin{array}{l}0.080 ; 0.023] \\
.116 ;-0.011] \\
0.050 ; 0.062] \\
\end{array}$ \\
\hline $\begin{array}{r}\text { Gender Gap [95\% Cl]: } \\
\text { mixed-gender/self-confi } \\
\text { mixed-gender/others } \\
\text { same-gender/self-confi } \\
\text { same-gender/others }\end{array}$ & & & & & & $\begin{array}{r}-0.040 \\
-0.053 \\
0.013 \\
0.034 \\
\end{array}$ & $\begin{array}{l}.128 ; 0.487] \\
.110 ; 0.003] \\
0.079 ; 0.105] \\
.028 ; 0.095] \\
\end{array}$ & & & & \\
\hline $\begin{array}{r}\text { Gender Gap [95\% Cl]: } \\
\text { mixed-gender/over-confi } \\
\text { mixed-gender/others } \\
\text { same-gender/over-confi } \\
\text { same-gender/others }\end{array}$ & & & & & & & & & & $\begin{array}{r}-0.048 \\
-0.065^{* *} \\
-0.066 \\
0.012 \\
\end{array}$ & $\begin{array}{l}0.261 ; 0.166] \\
.118 ;-0.116] \\
0.285 ; 0.152] \\
0.045 ; 0.070] \\
\end{array}$ \\
\hline
\end{tabular}

Note: Displayed are average marginal effects on the decision to enter competition (vector of (0-1) choices made in 8 competition-involving choice sets). Bases are estimations of Population-Average Logistic Regression Models controlling for socio-economic factors. Exchangeable error correlations are used and a panel robust estimate of the variance-covariance matrix of the estimator corrects tiny standard errors for any dependency over rounds for a given individual. $* \mathrm{p}<0.10$, ** $\mathrm{p}<0.05, * * * \mathrm{p}<0.01$. self-confi equals 1 if choices in competition-free choice sets always equal 1 , otherwise it equals 0 (=others). Same with over-confi that additionally adjusts for the correctness of these decisions on the basis of subject's personal ability, otherwise it equals 0 (=others).

in general do not play any role in explaining women's same-gender competition preferences in our experiment: neither risk willingness, nor ability, nor self-confidence: As regards an average woman's risk-willingness, we can only find a very small explanatory power in the full-time employed women subsample. Here it matters insofar as the data point to a negative relationship in the following sense: Women are more prone to select into same-gender competition if they rate themselves as not being risk-loving. Similarly, ability provides no further evidence for the gender-pairing phenomenon and does not even explain part of the general competition willingness gender gap in our experiment, which is documented in other studies (see e.g. Buser et al., 2014). Notwithstanding, our participating women are indeed less able to perform on this type of task compared to men and men's competition willingness is indeed affected.

In line with the literature are our findings regarding self-confidence and its relevance for the gender gap in competition. First of all, we detect a substantive gender gap in self-confidence 
with women being less prone to take self-confident decisions. Second, we identify a person's self-confidence, when only an assessment of own ability rather than of others is needed, to be a mediating factor for both genders such that the gender gap in a mixed-gender competition environment is eliminated among the self-confident participants. Notwithstanding, there is a substantive positive relationship between one's self-confidence and the decision to compete regardless of competition group's gender-mix. However, self-confidence does not provide any additional, measurable explanation for women's same-gender competition preferences. However, when evaluating whether ones self-confidence is legitimate in comparison with others, over-confidence is a better measure. For this, it becomes evident that besides a very high samegender competition entry rate among the over-confident women, i.e. women who over-estimate their own achievements but none the less throw their hat in the ring and compete, competition entry rate in a mixed-gender setting is equally likely either way. The gap between same- and mixed-gender competition willingness is only present among those competition willing women who correctly or even under-estimate their personal achievements.

We interpret our findings in accordance with gender stereotypic beliefs that women seem to have regarding their perception of competitors' ability: same-gender competitors are perceived to be less able than opposite gender competitors. Only over-confident women do not make this distinction any longer, since they are equally likely to compete. Estimating others' achievements is related to the uncertainty of a setting, which in turn correlates with the competition pressure of the setting and could therefore be biased. We find support in the fact that this biased perception is less evident among the over-confident women, where a gender-mix effect does not emerge. From this point of view, do our results expand prior findings on the issue of selection into competition by offering an explanation why same-gender competitions are preferred: A group of women is seen to be a more favorable constellation so that competition is preferred even if the conditions are impeded by risk and difficulty. In this respect, we see our results in line with the Goldberg paradigm, in honor of a study by Goldberg (1968), who found that women have great prejudices about other women ${ }^{30}$ Another but related parallel could be drawn to the crabbucket mentality phenomenon, which is observed in the workplace when women hindering other women in making progress in their careers. This phenomenon has been discussed in different domains with the conclusion that women have a lower opinion about other women (Marques, 2009 , Jogulu \& Vijayasingham, 2015).

Even in economics models is that underlying relationship with stereotypes already acknowledged. See for example the paper by Bordalo et al. (2016). Their model allows gender stereotypes and self-assessments to be related with each other so that gender stereotypes even predict individual behavior and a same-gender preference to be interpreted from the point of view that changing the gender-mix of the competitors group also changes self-stereotypes. In line with that theoretical reflections are studies that explicitly vary the stereotypical perceived domain in which people are experimentally observed and that demonstrate that this determines behavioral outcomes (Coffman, 2014; Dreber et al., 2011; Kamas \& Preston, 2012, Shurchkov, 2012).

We also like to emphasize another important factor: the experimental setting of a framed field

\footnotetext{
${ }^{30}$ See also Eagly \& Karau $\sqrt{2002)}$ for a literature review related to stereotypes about female leadership.
} 
study in an online context. Most findings on whether women shy away from competition in general or only from a mixed-gender competition build on laboratory experiments in highly stylized settings if not school settings with children from different schooling backgrounds (Booth \& Nolen, 2012a). Even the findings by Niederle \& Vesterlund (2007) build on laboratory experiments in highly stylized settings, however they provide the basis for the development of lab experiments into the field. To our knowledge, there exists no other controlled experimental study with an anonymous but nonetheless close-to-reality environment 31 Imagine for instance, the decision to apply for a job is a complex issue but is prepared in an anonymous environment without knowing other applicants. The anonymity as well as the gender-mix of the competitors group might be responsible for this phenomenon and women may dislike a specific gender make-up of the competition group. In this paper we demonstrate that if women are willing to compete, they prefer women-only competitive environments.

The advantage of our experiment is that it provides a more realistic setting plus randomization compared to naturally occurring data (List, 2011). We made an attempt to transfer research on competition willingness with the help of an experimental design that adapts real world scenarios. An online experiment gave us the chance to study de facto experimentally inexperienced participants in their natural environments and to avoid a highly stylistic classroom setting. For exactly that reason, our data provide helpful insights for future research on determinants for self-selection into competition.

\section{References}

Apicella, C. L., Demiral, E. E., \& Mollerstrom, J. (forthcoming). No Gender Difference in Willingness to Compete When Competing against Self. American Economic Review, Papers and Proceedings.

Bagues, M. F., \& Esteve-Volart, B. (2010). Can Gender Parity Break the Glass Ceiling? Evidence from a Repeated Randomized Experiment. Review of Economic Studies, 77, 1301-1328.

Beblo, M., Beninger, D., Burow, N., \& Schröder, M. (2017). Self-Selection and Conditional Performance: The Gender Pay Gap in a Choice Experiment. mimeo.

Ben-Ner, A., Kong, F., \& Putterman, L. (2004). Share and Share Alike? Gender-Pairing, Personality, and Cognitive Ability as Determinants of Giving. Journal of Economic Psychology, $25,581-589$.

Booth, A., \& Nolen, P. (2012a). Choosing to Compete: How Different are Girls and Boys? Journal of Economic Behavior and Organization, 81, 542-555.

\footnotetext{
${ }^{31}$ Boschini et al. (2014) conduct telephone interviews with a large representative sample in Sweden. Contrary to their study where the gender of the experimenter, i.e. the interviewer, is not anonymous to the participants with potential priming effects to be caused (e.g. men being more competitive when interviewed by a woman than by a man, p. 29), subjects in our experiment receive no information about the experimenter other than that they are taking part in a scientific study with information about the researcher team given at the end of the experiment.
} 
Booth, A. L., \& Nolen, P. (2012b). Gender Differences in Risk Behaviour: Does Nurture Matter? The Economic Journal, 122, F56-F78.

Bordalo, P., Coffman, K., Gennaioli, N., \& Shleifer, A. (2016). Stereotypes. The Quarterly Journal of Economics, 131, 1753-1794.

Boschini, A., Dreber, A., von Essen, E., Muren, A., \& Ranehill, E. (2014). Gender and Economic Preferences in a Large Random Sample volume 2014:6 of Research Papers in Economics. Stockholm University, Department of Economics.

Brandts, J., Groenert, V., \& Rott, C. (2015). The Impact of Advice on Women's and Men's Selection into Competition. Management Science, 61, 1018-1035.

Broder, I. E. (1993). Review of NSF Economics Proposals: Gender and Institutional Patterns. American Economic Review, 83, 964-970.

Buckley, N. J., Cuff, K., Hurley, J., McLeod, L., Mestelman, S., \& Cameron, D. (2012). An Experimental Investigation of Mixed Systems of Public and Private Health Care Finance. Journal of Economic Behavior and Organization, 84, 713-729.

Buser, T., Niederle, M., Oosterbeek, H., Buser, T., Niederle, M., \& Oosterbeek, H. (2014). Gender, Competitiveness, and Career Choices. The Quarterly Journal of Economics, 129, 1409-1447.

Butler, J. V. (2016). Inequality and Relative Ability Beliefs. The Economic Journal, 126, 907-948.

Chen, Z., Ong, D., \& Sheremeta, R. M. (2015). The Gender Difference in the Value of Winning. Economics Letters, 137, 226-229.

Coffman, K. B. (2014). Evidence on Self-Stereotyping and the Contribution of Ideas. The Quarterly Journal of Economics, 129, 1625-1660.

Datta Gupta, N., Poulsen, A., \& Villeval, M.-C. (2013). Gender Matching and Competitiveness: Experimental Evidence. Economic Inquiry, 51, 816-835.

Di Cagno, D., Galliera, A., Güth, W., Pace, N., Panaccione, L., Galliera, A., Güth, W., Pace, N., \& Panaccione, L. (2016). Make-up and Suspicion in Bargaining with Cheap Talk: An Experiment Controlling for Gender and Gender Constellation. Theory and Decision, 80, 463-471.

Dittrich, M., Knabe, A., \& Leipold, K. (2014). Gender Differences in Experimental Wage Negotiations. Economic Inquiry, 52, 862-873.

Dohmen, T., Falk, A., Huffman, D., Sunde, U., Schupp, J., \& Gert G. Wagner (2011). Individual Risk Attitudes: Measurement, Determinants, And Behavioral Consequences. Journal of the European Economic Association, 9, 522-550.

Dreber, A., Essen, E., \& Ranehill, E. (2011). Outrunning the Gender Gap-Boys and Girls Compete Equally. Experimental Economics, 14, 567-582. 
Eagly, A. H., \& Karau, S. J. (2002). Role Congruity Theory of Prejudice Toward Female Leaders. Psychological Review, 109, 573-598.

Eckel, C. C., \& Grossman, P. J. (2001). Chivalry and Solidarity in Ultimatum Games. Economic Inquiry, 39, 171-188.

Edelman, B. (2012). Using Internet Data for Economic Research. Journal of Economic Perspectives, 26, 189-206.

Gneezy, U., Niederle, M., \& Rustichini, A. (2003). Performance in Competitive Environments: Gender differences. The Quarterly Journal of Economics, 118, 1049-1074.

Goldberg, P. (1968). Are Women Prejudiced Against Women? Trans-action, 5, 28-30.

Harrison, G. W. (2007). Making Choice Studies Incentive Compatible: Chapter 4. In B. J. Kanninen (Ed.), Valuing Environmental Amenities Using Stated Choice Studies (pp. 67-110). Dordrecht: Springer volume 8 of The economics of non-market goods and resources.

Harrison, G. W., \& List, J. A. (2004). Field Experiments. Journal of Economic Literature, 42, 1009-1055.

Horton, J. J., Rand, D. G., \& Zeckhauser, R. J. (2011). The Online Laboratory: Conducting Experiments in a Real Labor Market. Experimental Economics, 14, 399-425.

Jogulu, U., \& Vijayasingham, L. (2015). Women Doctors, on Working With Each Other. Gender in Management: An International Journal, 30, 162-178.

Kamas, L., \& Preston, A. (2012). The Importance of Being Confident; Gender, Career Choice, and Willingness to Compete. Journal of Economic Behavior and Organization, 83, 82-97.

Lee, S., Niederle, M., \& Kang, N. (2014). Do Single-Sex Schools Make Girls More Competitive? Economics Letters, 124, 474-477.

List, J. A. (2011). Why Economists Should Conduct Field Experiments and 14 Tips for Pulling One Off. Journal of Economic Perspectives, 25, 3-16.

Lönnqvist, J.-E., Verkasalo, M., Walkowitz, G., \& Wichardt, P. C. (2015). Measuring Individual Risk Attitudes in the Lab: Task or Ask? An Empirical Comparison. Journal of Economic Behavior \& Organization, 119, 254-266.

Marques, J. (2009). Sisterhood in short supply in the workplace. Human Resource Management International Digest, 17, 28-31.

Moore, D. A., \& Healy, P. J. (2008). The Trouble with Overconfidence. Psychological Review, $115,502-517$.

Nekby, L., Thoursie, P. S., \& Vahtrik, L. (2008). Gender and Self-Selection into a Competitive Environment: Are Women More Overconfident than Men? Economics Letters, 100, 405-407. 
Nelson, J. A. (2014). Are Women Really More Risk-Averse than Men? A Re-Analysis of the Literature Using Expanded Methods. Journal of Economic Surveys, (pp. 1-20).

Newton, D., \& Simutin, M. (2014). Of Age, Sex, and Money: Insights from Corporate Officer Compensation on the Wage Inequality Between Genders. Management Science, (pp. 1-21).

Niederle, M. (2016). Gender. In J. H. Kagel, \& A. E. Roth (Eds.), The Handbook of Experimental Economics Handbooks in Economics (pp. 481-553). Princeton and Oxford: Princeton University Press.

Niederle, M., Segal, C., \& Vesterlund, L. (2013). How Costly Is Diversity? Affirmative Action in Light of Gender Differences in Competitiveness. Management Science, 59, 1-16.

Niederle, M., \& Vesterlund, L. (2007). Do Women Shy Away From Competition? Do Men Compete Too Much? The Quarterly Journal of Economics, 122, 1067-1101.

Niederle, M., \& Vesterlund, L. (2011). Gender and Competition. Annual Review of Economics, 3, 601-630.

Olsson, H. (2014). Measuring Overconfidence: Methodological Problems and Statistical Artifacts. Journal of Business Research, 67, 1766-1770.

Rapoport, A., \& Chammah, A. M. (1965). Sex Differences in Factors Contributing to the Level of Cooperation in the Prisoner's Dilemma Game. Journal of personality and social psychology, 2, 831-838.

Shurchkov, O. (2012). Under Pressure: Gender Differences in Output Quality and Quantity under Competition and Time Constraints. Journal of the European Economic Association, 10, 1189-1213.

Sutter, M., Bosman, R., Kocher, M. G., \& Winden, F. (2009). Gender Pairing and BargainingBeware the Same Sex! Experimental Economics, 12, 318-331.

van Veldhuizen, R. (2016). Gender Differences in Tournament Choices: Risk Preferences, Overconfidence or Competitiveness? volume SP II 2016-207 of Discussion Papers. Berlin: Wissenschaftszentrum Berlin für Sozialforschung. 


\section{A Appendix}

Screenshots as they appeared on subjects desktop

The trial mazes (left hand side: easy, right hand side: hard):
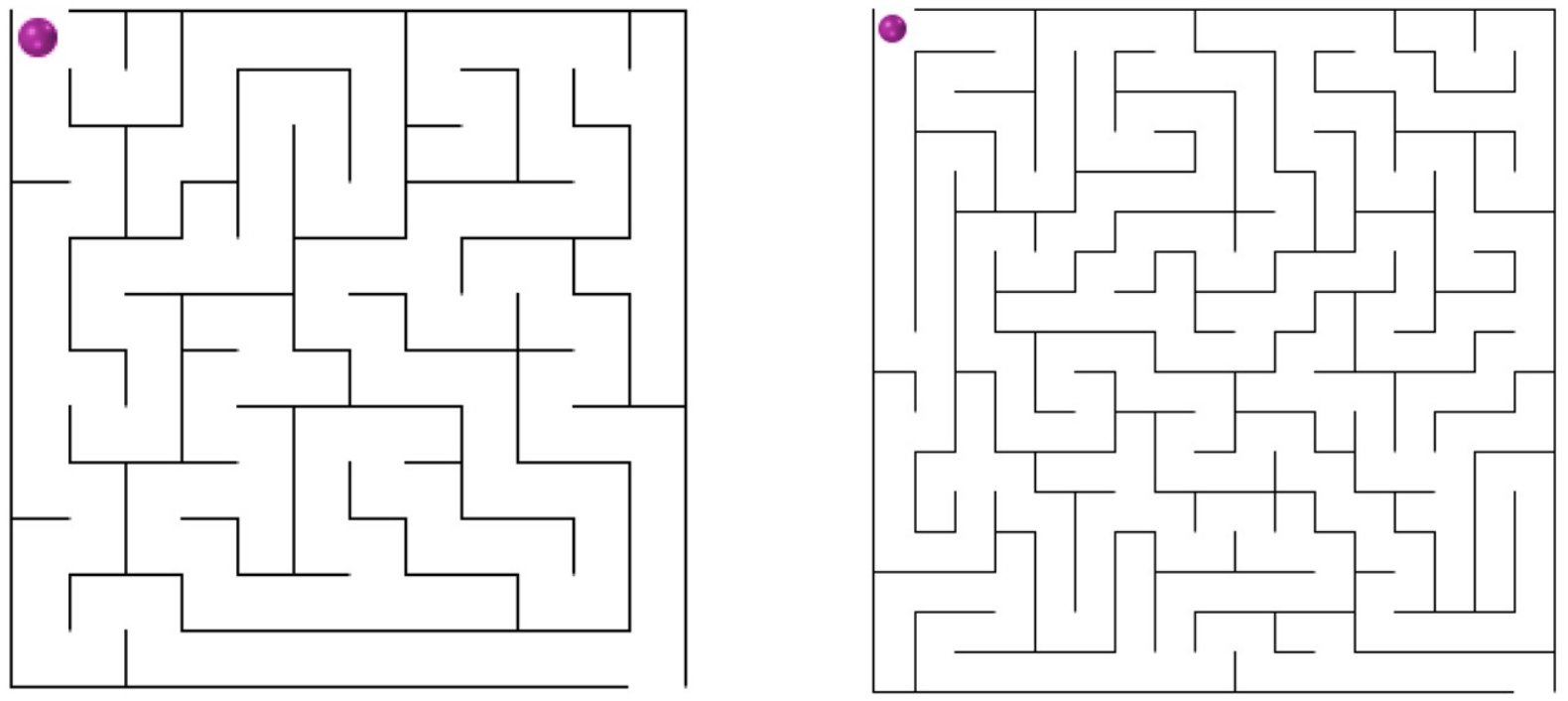
Choice Set 5, low spread with easy difficulty, no competition:

\begin{tabular}{|c|c|c|}
\hline \multicolumn{3}{|c|}{$\begin{array}{l}\text { Choose one of the two options. } \\
\text { If this choice set is drawn at the end of this study, } \\
\text { the selected option will be the basis of your payment. }\end{array}$} \\
\hline $\begin{array}{l}\text { Option A } \\
\text { level of difficulty: easy }\end{array}$ & level of dif & $\begin{array}{l}\text { Option B } \\
\text { ulty: easy }\end{array}$ \\
\hline for each solved maze & 20 cents & $\begin{array}{l}\text { for each solved maze } \\
\text { (at least } 5 \text { mazes) } \\
\text { for each solved maze } \\
\text { (less than } 5 \text { mazes) }\end{array}$ \\
\hline $\begin{array}{l}\text { Explanation: } \\
\text { You receive } 50 \text { cents for each solved maze with } \\
\text { an easy level of difficulty. }\end{array}$ & $\begin{array}{l}\text { Explanati } \\
\text { You recei } \\
\text { easy diff } \\
\text { mazes. If } \\
\text { each solv }\end{array}$ & $\begin{array}{l}1 € \text { for each solved maze with an } \\
\text { ulty level if you solve at least } 5 \\
\text { ou don't you will get } 20 \text { cents for } \\
\text { maze. }\end{array}$ \\
\hline
\end{tabular}

Choice Set 8, high spread with easy difficulty, no competition:

\section{Choose one of the two options.}

If this choice set is drawn at the end of this study,

the selected option will be the basis of your payment.

\begin{tabular}{|c|c|}
\hline $\begin{array}{l}\text { Option A } \\
\text { level of difficulty: hard }\end{array}$ & $\begin{array}{l}\text { Option B } \\
\text { level of difficulty: easy }\end{array}$ \\
\hline for each solved maze & $\begin{array}{ll}2 € & \begin{array}{l}\text { for each solved maze } \\
\text { (at least } 5 \text { mazes) }\end{array} \\
5 \text { cents } & \begin{array}{c}\text { for each solved maze } \\
\text { (less than } 5 \text { mazes) }\end{array}\end{array}$ \\
\hline $\begin{array}{l}\text { Explanation: } \\
\text { You receive } \mathbf{5 0} \text { cents for each solved maze with a } \\
\text { hard level of difficulty. }\end{array}$ & $\begin{array}{l}\text { Explanation: } \\
\text { You receive } \mathbf{2} \text { for each solved maze with an } \\
\text { easy difficulty level if you solve at least } 5 \\
\text { mazes. If you don't you will get } 5 \text { cents for } \\
\text { each solved maze. }\end{array}$ \\
\hline
\end{tabular}

Choice Set 11, low spread with easy difficulty, mixed-gender competition:

\begin{tabular}{|c|c|c|}
\hline \multicolumn{3}{|c|}{$\begin{array}{l}\text { Choose one of the two options. } \\
\text { If this choice set is drawn at the end of this study, } \\
\text { the selected option will be the basis of your payment. }\end{array}$} \\
\hline \multirow{2}{*}{$\begin{array}{l}\text { Option A } \\
\text { level of difficulty: easy }\end{array}$} & \multirow{2}{*}{\multicolumn{2}{|c|}{$\begin{array}{l}\text { Option B } \\
\text { level of difficulty: easy }\end{array}$}} \\
\hline & & \\
\hline \multirow[t]{2}{*}{50 cents for each solved maze } & $1 €$ & $\begin{array}{l}\text { for each solved maze } \\
(\text { among the best } 30 \%)\end{array}$ \\
\hline & 20 cents & $\begin{array}{l}\text { for each solved maze } \\
\text { (if you'r not among the best 30\%) }\end{array}$ \\
\hline $\begin{array}{l}\text { Explanation: } \\
\text { You receive } 50 \text { cents for each solved maze with } \\
\text { an easy level of difficulty. }\end{array}$ & \multicolumn{2}{|c|}{$\begin{array}{l}\text { Explanation: } \\
\text { You receive } 1 € \text { for each solved maze with an } \\
\text { easy difficulty level if you rank among the } \\
\text { best } 30 \% \text { of all participants. If you don't you will } \\
\text { get } 20 \text { cents for each solved maze. }\end{array}$} \\
\hline
\end{tabular}


Choice Set 14, high spread with easy difficulty, mixed-gender competition:

\begin{tabular}{|c|c|c|}
\hline \multicolumn{3}{|c|}{$\begin{array}{l}\text { Choose one of the two options. } \\
\text { If this choice set is drawn at the end of this study, } \\
\text { the selected option will be the basis of your payment. }\end{array}$} \\
\hline \multirow{2}{*}{$\begin{array}{l}\text { Option A } \\
\text { level of difficulty: easy }\end{array}$} & & Option B \\
\hline & \multicolumn{2}{|c|}{ level of difficulty: easy } \\
\hline \multirow[t]{2}{*}{50 cents for each solved maze } & $2 €$ & $\begin{array}{l}\text { for each solved maze } \\
\text { (among the best } 30 \% \text { ) }\end{array}$ \\
\hline & 5 cents & $\begin{array}{l}\text { for each solved maze } \\
\text { (if you'r not among the best } 30 \% \text { ) }\end{array}$ \\
\hline $\begin{array}{l}\text { Explanation: } \\
\text { You receive } \mathbf{5 0} \text { cents for each solved maze with } \\
\text { an easy level of difficulty. }\end{array}$ & \multicolumn{2}{|c|}{$\begin{array}{l}\text { Explanation: } \\
\text { You receive } \mathbf{2 €} \text { for each solved maze with an } \\
\text { easy difficulty level if you rank among the } \\
\text { best } 30 \% \text { of all participants. If you don't you will } \\
\text { get } 5 \text { cents for each solved maze. }\end{array}$} \\
\hline
\end{tabular}

Choice Set 17, low spread with easy difficulty, same-gender competition (women):

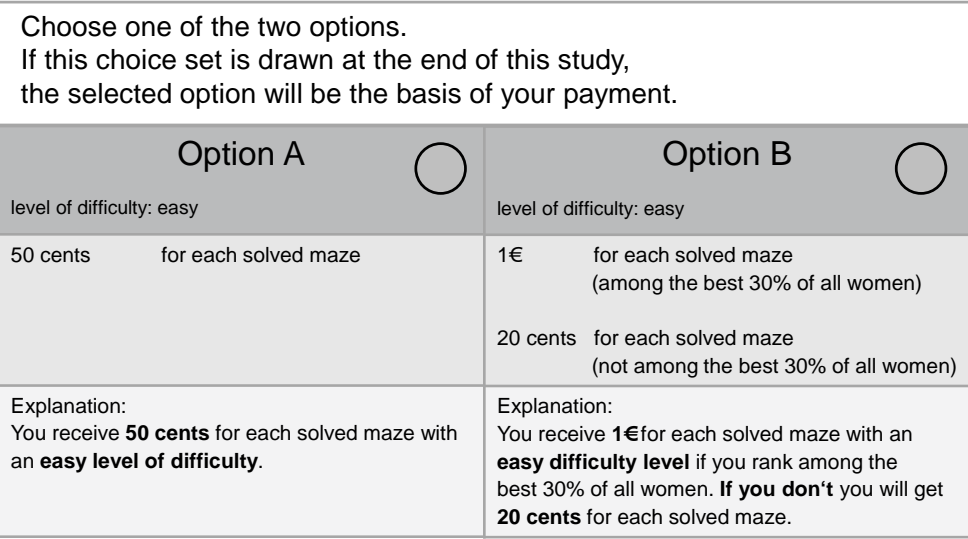

Choice Set 20, high spread level with easy difficulty, same-gender competition (women):

\begin{tabular}{|c|c|c|}
\hline \multicolumn{3}{|c|}{$\begin{array}{l}\text { Choose one of the two options. } \\
\text { If this choice set is drawn at the end of this study, } \\
\text { the selected option will be the basis of your payment. }\end{array}$} \\
\hline \multirow{2}{*}{$\begin{array}{l}\text { Option A } \\
\text { level of difficulty: easy }\end{array}$} & \multirow{2}{*}{\multicolumn{2}{|c|}{ Option B }} \\
\hline & & \\
\hline for each solved maze & & $\begin{array}{l}\text { for each solved maze } \\
\text { (among the best } 30 \% \text { of all women) }\end{array}$ \\
\hline & 5 cents & $\begin{array}{l}\text { for each solved maze } \\
\text { (not among the best } 30 \% \text { of all women) }\end{array}$ \\
\hline $\begin{array}{l}\text { Explanation: } \\
\text { You receive } 50 \text { cents for each solved maze with } \\
\text { an easy level of difficulty. }\end{array}$ & $\begin{array}{l}\text { Explane } \\
\text { You rec } \\
\text { easy di } \\
\text { best } 30 \\
\mathbf{5} \text { cents }\end{array}$ & $\begin{array}{l}\text { ion: } \\
\text { ive } 2 € \text { for each solved maze with an } \\
\text { ficulty level if you rank among the } \\
\text { of all women. If you don't you will get } \\
\text { for each solved maze. }\end{array}$ \\
\hline
\end{tabular}




\section{B Appendix}

\section{Choice Sets in groups}

1st group: Choice 1-2 - Difficulty 32

\begin{tabular}{|c|c|c|}
\hline \multicolumn{2}{|c|}{ Choice Set 1 } \\
\hline & Option A & Option B \\
\hline Difficulty & easy & hard \\
\hline & \multicolumn{2}{|c|}{ low } \\
\hline Spread & \multicolumn{2}{|c|}{1.00} \\
\hline Wage $(€)$ & $0.50 \quad \begin{array}{c}\text { self-estimation: } \\
\text { beliefs about one's own } \\
\text { ability }\end{array}$ \\
\hline
\end{tabular}

\begin{tabular}{|c|c|c|}
\hline \multicolumn{2}{|l|}{ Choice Set 2 } \\
\hline & Option A & Option B \\
\hline Difficulty & easy & hard \\
\hline & \multicolumn{2}{|c|}{ high } \\
\hline Spread & \multicolumn{2}{|c|}{2.00} \\
\hline Wage (€) & $0.50 \quad \begin{array}{c}\text { self-estimation: } \\
\text { beliefs about one's own } \\
\text { ability }\end{array}$ \\
\hline
\end{tabular}

2nd group: Choice Set 3-4 - Performance vs. Competition 33

\begin{tabular}{|c|c|c|c|c|c|}
\hline \multicolumn{3}{|l|}{ Choice Set 3} & \multicolumn{3}{|l|}{ Choice Set 4} \\
\hline & Option A & Option B & & Option A & Option B \\
\hline Performance & \multicolumn{2}{|c|}{ threshold } & Performance & \multicolumn{2}{|c|}{ threshold } \\
\hline Difficulty & \multicolumn{2}{|c|}{ hard } & Difficulty & \multicolumn{2}{|c|}{ hard } \\
\hline Competition & no & yes, mixed & Competition & no & yes, mixed \\
\hline Spread & \multicolumn{2}{|c|}{ low } & Spread & \multicolumn{2}{|c|}{ high } \\
\hline Wage $(€)$ & $(0.20 ; 1.00)$ & $(0.20 ; 1.00)$ & Wage $(€)$ & $(0.05 ; 2.00)$ & $(0.05 ; 2.00)$ \\
\hline & $\begin{array}{c}\text { self- } \\
\text { estimation: } \\
\text { beliefs about } \\
\text { one's own } \\
\text { ability }\end{array}$ & $\begin{array}{l}\text { self- } \\
\text { placement: } \\
\text { beliefs about } \\
\text { one's own } \\
\text { relative to } \\
\text { others' ability }\end{array}$ & & $\begin{array}{c}\text { self- } \\
\text { estimation: } \\
\text { beliefs about } \\
\text { one's own } \\
\text { ability }\end{array}$ & $\begin{array}{c}\text { self- } \\
\text { placement: } \\
\text { beliefs about } \\
\text { one's own } \\
\text { relative to } \\
\text { others' ability }\end{array}$ \\
\hline
\end{tabular}

\footnotetext{
${ }^{32}$ Group is not selected for the present paper.

${ }^{33}$ Group is not selected for the present paper.
} 
3rd group: Choice Set 5-10 - Performance vs. Performance-threshold

\begin{tabular}{|c|c|c||c|c|c|}
\hline \multicolumn{5}{|l|}{ Choice Set 5} & \multicolumn{2}{|l|}{ Choice Set 8} \\
\hline & Option A & Option B & & Option A & Option B \\
\cline { 2 - 6 } Performance & linear & threshold & Performance & linear & threshold \\
\hline Difficulty & easy & easy & Difficulty & easy & easy \\
\hline Spread & \multicolumn{2}{|c|}{ low } & Spread & \multicolumn{2}{|c|}{ high } \\
\hline Wage $(€)$ & 0.50 & $(0.2 ; 1.00)$ & Wage $(€)$ & 0.50 & $(0.05 ; 2.00)$ \\
\hline
\end{tabular}

\begin{tabular}{|c|c|c||c|c|c|}
\hline Choice Set 6 & Choice Set 9 \\
\hline & Option A & Option B & & Option A & Option B \\
\hline Performance & linear & threshold & Performance & linear & threshold \\
\hline Difficulty & hard & easy & Difficulty & hard & easy \\
\hline & \multicolumn{2}{|c|}{ low } & & & \\
\hline Spread & 0.50 & $(0.2 ; 1.00)$ & Spread & \multicolumn{2}{|c|}{ high } \\
\hline Wage $(€)$ & \multicolumn{2}{|l}{$(€)$} & 0.50 & $(0.05 ; 2.00)$ \\
\hline
\end{tabular}

\begin{tabular}{|c|c|c||c|c|c|}
\hline Choice Set 7 & Choice Set 10 \\
\hline & Option A & Option B & & Option A & Option B \\
\hline Performance & linear & threshold & Performance & linear & threshold \\
\hline Difficulty & hard & hard & Difficulty & hard & hard \\
\hline Spread & \multicolumn{2}{|c|}{ low } & & \multicolumn{2}{|c|}{ high } \\
\hline Wage $(€)$ & 0.50 & $(0.2 ; 1.00)$ & Wage $(€)$ & 0.50 & $(0.05 ; 2.00)$ \\
\hline & $\begin{array}{l}\text { self-estimation: beliefs } \\
\text { about one's own ability }\end{array}$ & & \multicolumn{2}{|c|}{$\begin{array}{c}\text { self-estimation: beliefs } \\
\text { about one's own ability }\end{array}$} \\
\hline
\end{tabular}


4th group: Choice Set 11-16 - Performance vs. Competition toward all participants (mixed-gender group)

\begin{tabular}{|c|c|c|}
\hline \multicolumn{3}{|c|}{ Choice Set 11 } \\
\hline & Option A & Option B \\
\hline Performance & linear & linear \\
\hline Difficulty & easy & easy \\
\hline Competition & no & mixed \\
\hline Spread & \multicolumn{2}{|c|}{ low } \\
\hline Wage $(€)$ & 0.50 & $(0.2 ; 1.00)$ \\
\hline
\end{tabular}

Choice Set 14

Choice Set 12

\begin{tabular}{|c|c|c|}
\hline & Option A & Option B \\
\hline Performance & linear & linear \\
\hline Difficulty & easy & easy \\
\hline Competition & no & mixed \\
\hline Spread & \multicolumn{2}{|c|}{ high } \\
\hline Wage $(€)$ & 0.50 & $(0.05 ; 2.00)$ \\
\hline
\end{tabular}

\begin{tabular}{|c|c|c|}
\hline \multicolumn{3}{|c|}{ Choice Set 12 } \\
\hline & Option A & Option B \\
\hline Performance & linear & linear \\
\hline Difficulty & hard & easy \\
\hline Competition & no & mixed \\
\hline Spread & \multicolumn{2}{|c|}{ low } \\
\hline Wage $(€)$ & 0.50 & $(0.2 ; 1.00)$ \\
\hline
\end{tabular}

Choice Set 15

\begin{tabular}{|c|c|c|}
\hline & Option A & Option B \\
\hline Performance & linear & linear \\
\hline Difficulty & hard & easy \\
\hline Competition & no & mixed \\
\hline Spread & \multicolumn{2}{|c|}{ high } \\
\hline Wage $(€)$ & 0.50 & $(0.05 ; 2.00)$ \\
\hline
\end{tabular}

\begin{tabular}{|c|c|c|}
\hline \multicolumn{2}{|c|}{ Choice Set 13 } \\
\hline & Option A & Option B \\
\hline Performance & linear & linear \\
\hline Difficulty & hard & hard \\
\hline Competition & no & mixed \\
\hline Spread & \multicolumn{2}{|c|}{ low } \\
\hline Wage $(€)$ & 0.50 & $(0.2 ; 1.00)$ \\
\hline & $\begin{array}{c}\text { self-placement: beliefs } \\
\text { about one's own relative to } \\
\text { others' ability }\end{array}$ \\
\hline
\end{tabular}

\begin{tabular}{|c|c|c|}
\hline \multicolumn{2}{|c|}{ Choice Set 16 } \\
\hline & Option A & Option B \\
\hline Performance & linear & linear \\
\hline Difficulty & hard & hard \\
\hline Competition & no & mixed \\
\hline Spread & \multicolumn{2}{|c|}{ high } \\
\hline Wage $(€)$ & 0.50 & $(0.05 ; 2.00)$ \\
\hline & \multicolumn{2}{|c|}{$\begin{array}{c}\text { self-placement: } \\
\text { beliefs about one's own } \\
\text { relative to others' ability }\end{array}$} \\
\hline
\end{tabular}


5th group: Choice Set 17-22 - Performance vs. Competition toward same gender participants

\begin{tabular}{|c|c|c|}
\hline \multicolumn{3}{|l|}{ Choice Set 17} \\
\hline & Option A & Option B \\
\hline Performance & linear & linear \\
\hline Difficulty & easy & easy \\
\hline Competition & no & same \\
\hline Spread & \multicolumn{2}{|c|}{ low } \\
\hline Wage $(€)$ & 0.50 & $(0.2 ; 1.00)$ \\
\hline
\end{tabular}

\begin{tabular}{|c|c|c|}
\hline \multicolumn{3}{|l|}{ Choice Set 20} \\
\hline & Option A & Option B \\
\hline Performance & linear & linear \\
\hline Difficulty & easy & easy \\
\hline \multirow[t]{2}{*}{ Competition } & no & same \\
\hline & \multicolumn{2}{|c|}{ high } \\
\hline Wage $(€)$ & 0.50 & $(0.05 ; 2.00)$ \\
\hline
\end{tabular}

\begin{tabular}{|c|c|c|}
\hline \multicolumn{3}{|c|}{ Choice Set 18} \\
\hline & Option A & Option B \\
\hline Performance & linear & linear \\
\hline Difficulty & hard & easy \\
\hline Competition & no & same \\
\hline Spread & \multicolumn{2}{|c|}{ low } \\
\hline Wage $(€)$ & 0.50 & $(0.2 ; 1.00)$ \\
\hline
\end{tabular}

Choice Set 21

\begin{tabular}{|c|c|c|}
\hline Choice Set 19 \\
\hline & Option A & Option B \\
\hline Performance & linear & linear \\
\hline Difficulty & hard & hard \\
\hline Competition & no & same \\
\hline Spread & \multicolumn{2}{|c|}{ low } \\
\hline Wage $(€)$ & 0.50 & $(0.2 ; 1.00)$ \\
\hline & $\begin{array}{r}\text { self-placement: } \\
\text { beliefs about one's own } \\
\text { relative to others' ability }\end{array}$ \\
\hline
\end{tabular}

\begin{tabular}{|c|c|c|}
\hline \multicolumn{3}{|l|}{ Choice Set 22} \\
\hline & Option A & Option B \\
\hline Performance & linear & linear \\
\hline Difficulty & hard & hard \\
\hline Competition & no & same \\
\hline Spread & \multicolumn{2}{|c|}{ high } \\
\hline \multirow[t]{2}{*}{ Wage $(€)$} & 0.50 & $(0.05 ; 2.00)$ \\
\hline & \multicolumn{2}{|c|}{$\begin{array}{l}\text { self-placement: } \\
\text { beliefs about one's own } \\
\text { relative to others' ability }\end{array}$} \\
\hline
\end{tabular}

6th group: Choice Set 23 - Rationality check 34

\begin{tabular}{|l|c|c|}
\hline \multicolumn{3}{|l|}{ Choice Set 23} \\
\hline & Option A & Option B \\
\hline & & \\
\hline Difficulty & hard & easy \\
\hline & & \\
\hline Wage $(€)$ & 0.50 & 1.00 \\
\hline
\end{tabular}

\footnotetext{
${ }^{34}$ Choice set is not selected for this present paper.
} 


\section{Appendix}

Table 6: Socio Economic and Demographic Statistics of Participants

\begin{tabular}{|c|c|c|c|c|c|}
\hline Variable & Observations & Mean & Standard Deviation & Min & Max \\
\hline Women* $^{*}$ & 414 & .505 & & & \\
\hline Age & & 35.920 & 7.540 & 25 & 51 \\
\hline Single* & & .502 & & & \\
\hline East Germany* & & .495 & & & \\
\hline Children in the household* & & .543 & & & \\
\hline Educational degree, no* & & .022 & & & \\
\hline Educational degree, low & & .449 & & & \\
\hline Educational degree, middle* & & .191 & & & \\
\hline Educational degree, high* & & .268 & & & \\
\hline Currently in education* & & .046 & & & \\
\hline Employment, full-time* & & .464 & & & \\
\hline Employment, part-time* & & .246 & & & \\
\hline Employment, other* & & .316 & & & \\
\hline Income & 389 & 3.401 & 1.401 & 0 & 7 \\
\hline Men & 405 & & & & \\
\hline Age & & 37.516 & 7.385 & 25 & 51 \\
\hline Single* & & .491 & & & \\
\hline East Germany* & & .501 & & & \\
\hline Children in the household* & & .338 & & & \\
\hline Educational degree, no* & & .022 & & & \\
\hline Educational degree, low* & & .427 & & & \\
\hline Educational degree, middle* & & .217 & & & \\
\hline Educational degree, high* & & .267 & & & \\
\hline Currently in education* & & .052 & & & \\
\hline Employment, full-time* & & .768 & & & \\
\hline Employment, part-time* & & .059 & & & \\
\hline Employment, other* & & .180 & & & \\
\hline Income & & 3.815 & 1.501 & 0 & 7 \\
\hline
\end{tabular}

Note: Characteristics are from the restricted sample upon which we base our analysis. ${ }^{*}$ denotes an indicator variable. Children in the household: at least one child lives in the household. Education: no degree $=$ no school, vocational training or university degree; low degree = vocational degree without Higher School-leaving Certificate; middle degree = vocational degree with Higher School-leaving Certificate; high degree = University or other institution of higher education. Employment, other: marginal employment, minijob, not regularly employed, occupational retraining, maternity or parental leave. Income: Personal gross monthly income is classified in categories $(1=0 €-500 € ; 2=501 €-1,000 € ; 3=1,001 €-2,000 €$; $4=2,001 €-3,000 € ; 5=3,001-4,000 € ; 6=4,001-5,000 € ; 7 \geq 5,001 €)$. 


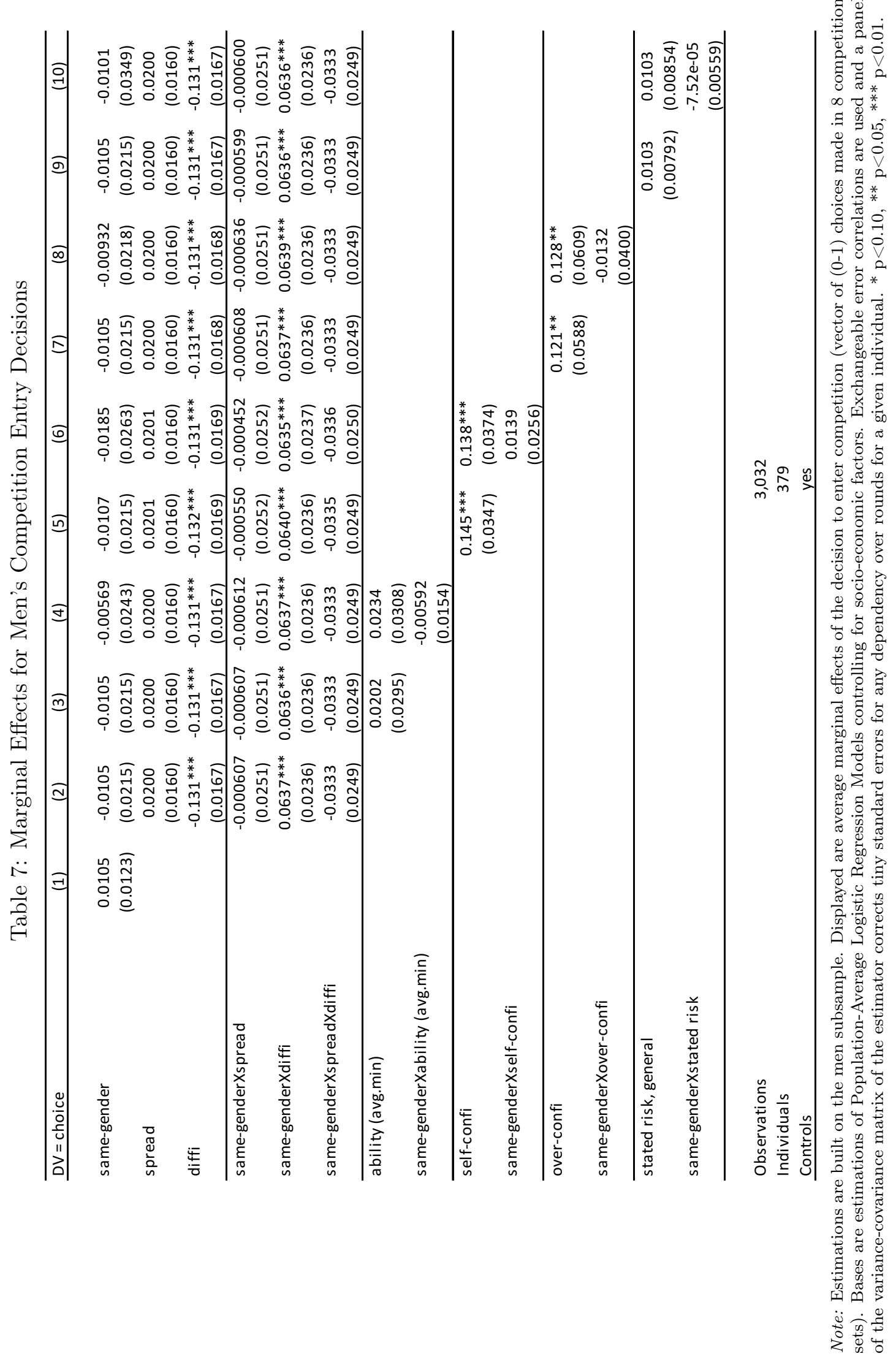


Figure 11: Mean Choices of Option B in Each Relevant Choice Set by Gender

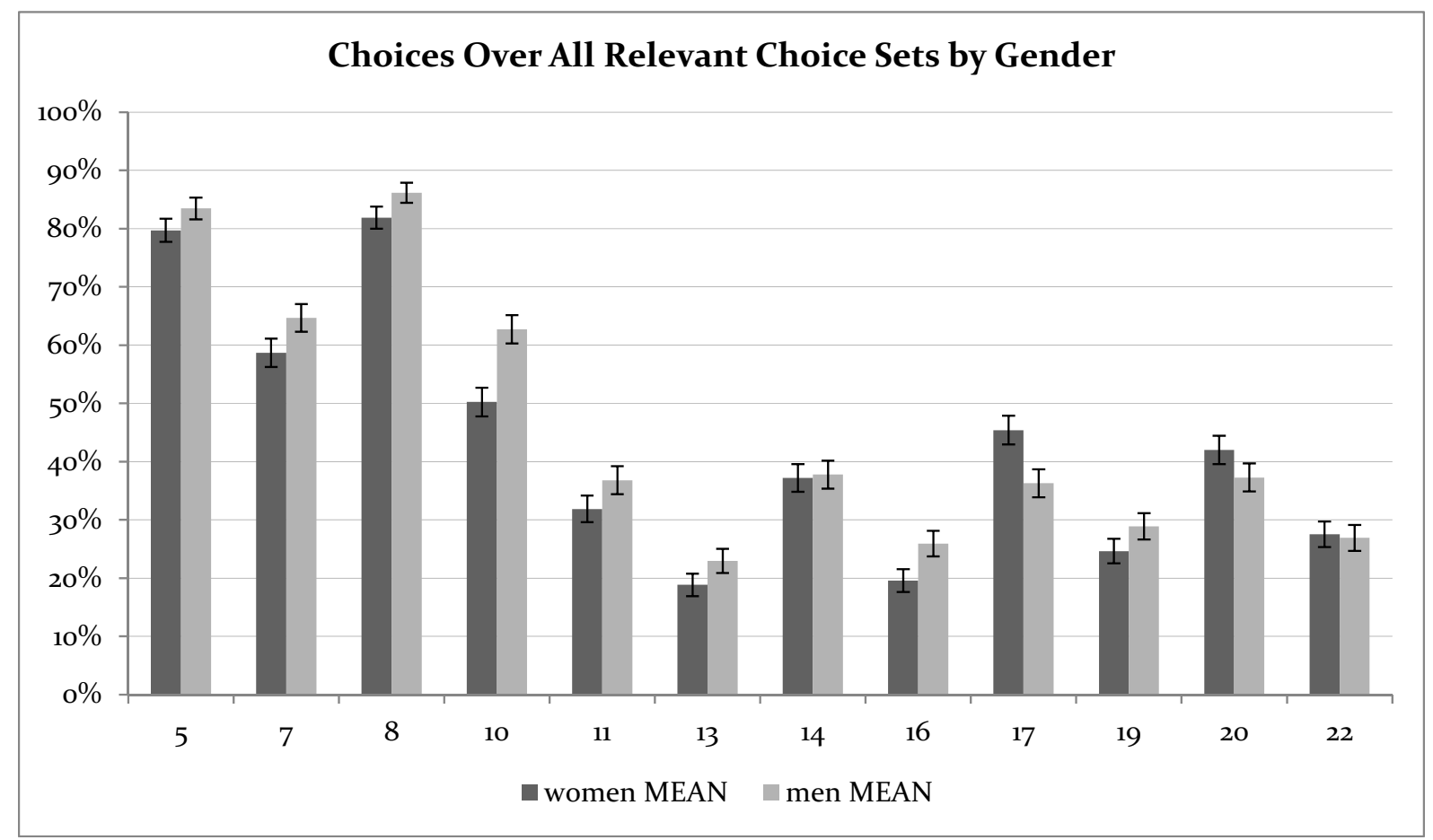

Note: Displayed are the mean values of option B choices with standard errors of the means by gender of the relevant choice sets.

Figure 12: Cumulative Distribution Function for Stated Risk Willingness by Gender

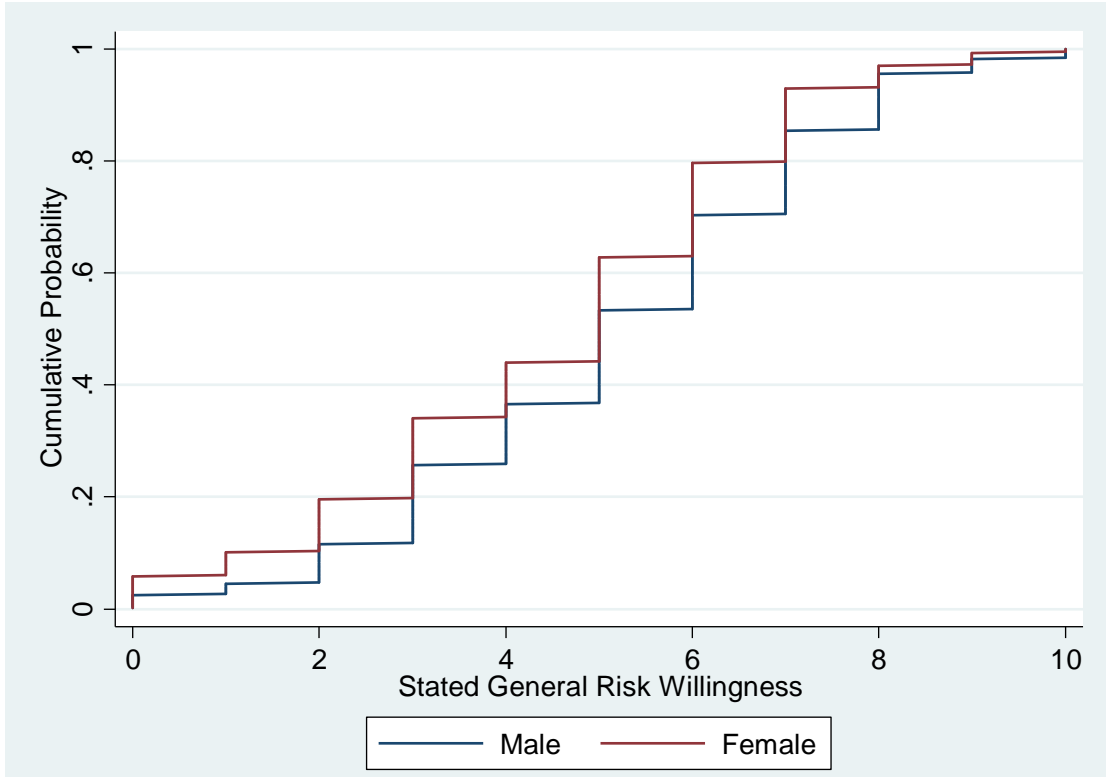

Note: Displayed is the cumulative distribution function of individual's general risk wilingness in the pre-experimental study. Data base on an eleven point risk-willingness scale from 0 to 10 , with 0 meaning not at all risk loving and 10 very much risk loving. 
Table 8: Actual Ability Distribution

\begin{tabular}{ccc}
\hline \multicolumn{3}{c}{$\begin{array}{c}\text { Summary Statistics of the Average Time (in } \\
\text { seconds) of Easy and Hard Level Trial Maze }\end{array}$} \\
\hline \hline Women & $\mathrm{N}$ & 414 \\
& Mean & 62.279 \\
& Median & 41.25 \\
& Standard Deviation & 61.336 \\
& 30th percentile & 30.5 \\
& 99th percentile & 303.5 \\
\hline Men & $\mathrm{N}$ & 405 \\
& Mean & 48.965 \\
& Median & 34.5 \\
& Standard Deviation & 41.743 \\
& 30th percentile & 25.5 \\
99th percentile & 200 \\
\hline
\end{tabular}

Note: The table displays the actual ability of the restricted sample when the 99th percentile of the overall ability distribution is eliminated; subjects who belong to the $1 \%$ of the slowest trial maze solvers (based on the average time for the hard and easy trial maze) separately by gender were excluded from the sample. Irrational voters at choice set \#23 are additionally restricted. Statistics on the whole sample are available from the authors upon request.

Figure 13: Actual Ability Distribution, Boxplots

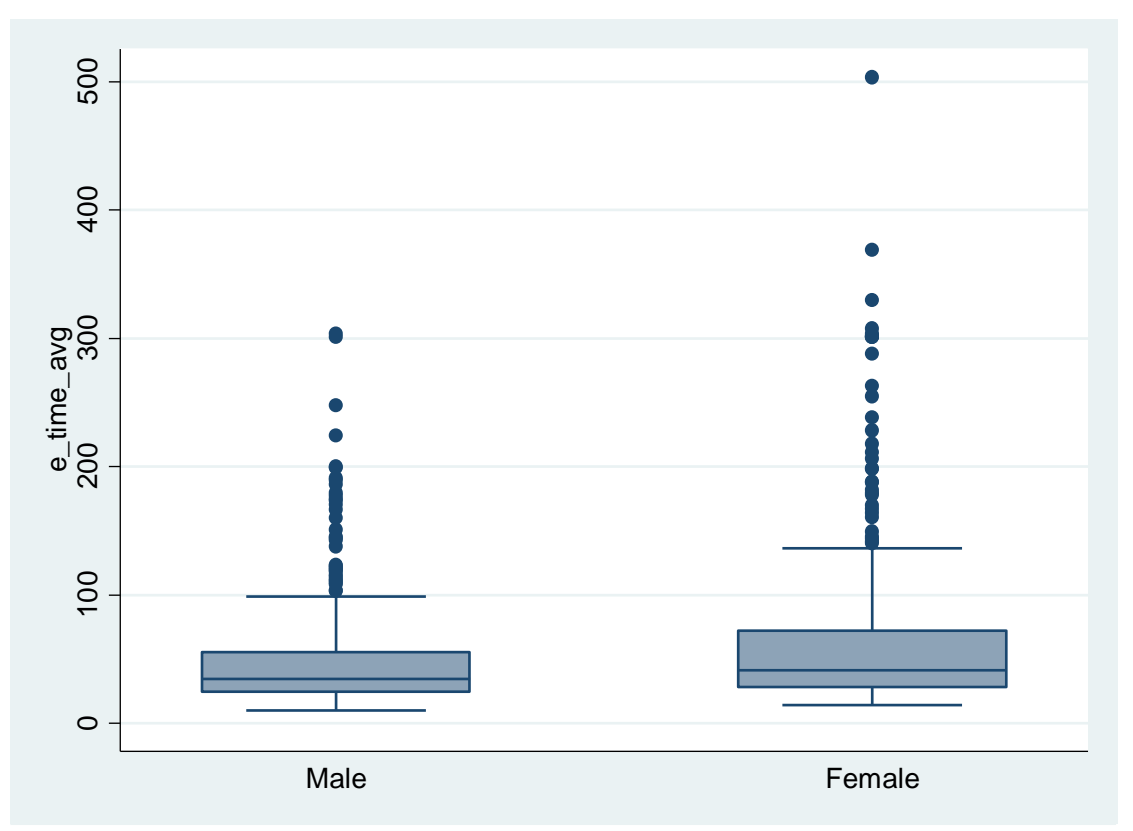

Note: Displayed are the boxplots of participants' actual ability based on the average time participants needed to solve the easy and hard level trial maze based on the restricted sample. 
Figure 14: Overall Competition Willingness by Individual Ability

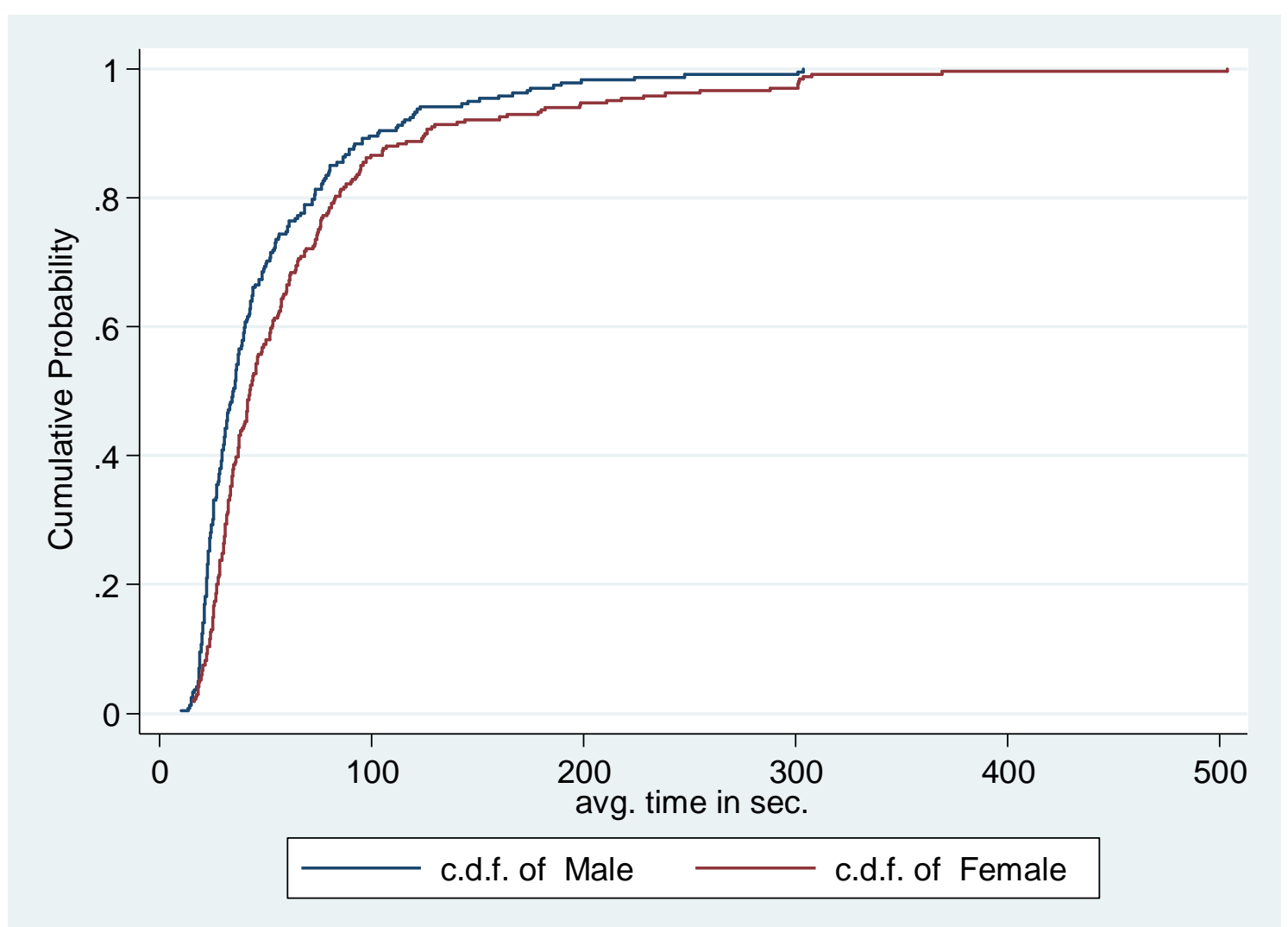

Note: Displayed are the cumulative distribution functions of competing subjects' ability, measured by the average time they actually needed to solve the easy and hard level trial maze

Table 9: Comparing SOEP Respondents and Experiment Full-Time Employed Women Sample

\begin{tabular}{ccccccc}
\hline Characteristics & \multicolumn{3}{c}{ FT Subjects in Experiment } & \multicolumn{3}{c}{ FT SOEP Respondents } \\
\hline \hline & Mean & sd & Median & Mean & sd & Median \\
\hline Monthly Gross Income (Category) & 1.775 & 0.688 & 2 & 1.836 & 0.643 & 2 \\
\hline Education & 1.953 & 0.939 & 2 & 1.861 & 0.903 & 2 \\
\hline Risk-Willingness & 4.599 & 2.242 & 5 & 4.695 & 2.007 & 5 \\
\hline
\end{tabular}

Note: Table reports key figures on our full-time (FT) employed female experiment subjects in comparison with respective respondents from the SOEP, (age 25-51, weighted data, v.29, 2012), which do not differ significantly. Bases for comparisons are 2 -sided t-tests. Characteristics are: (1) the monthly gross income by category with $1=0 €-500 € ; 2=501 €-1,000 €$; $3=1,001 €-2,000 € ; 4=2,001 €-3,000 € ; 5=3,001-4,000 € ; 6=4,001-5,000 € ; 7 \geq 5,001 € ;(2)$ education by category with $0=$ no degree or formal education - meaning no school, vocational training or university degree; $1=$ low degree, meaning vocational degree without Higher School-leaving Certificate; $2=$ middle degree, meaning vocational degree with Higher School-leaving Certificate; $4=$ high degree, meaning university or other institution of higher education; (3) self-reported risk scores in the pre-experimental study on an eleven point risk-willingness scale from 0 to 10 , with 0 meaning not at all risk loving and 10 very much risk loving in general. 
Figure 15: Comparing SOEP Respondents and Experiment Full-Time Employed Women Sample, Cumulative Distribution Function for Stated Risk Willingness

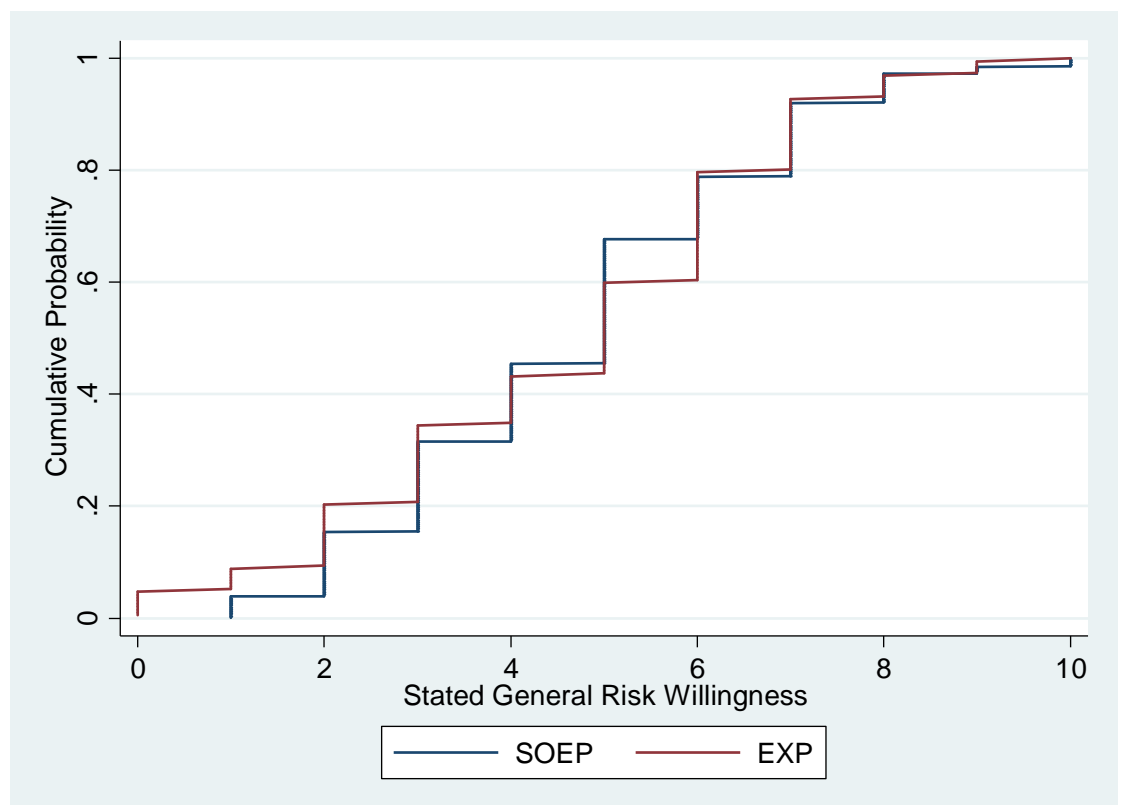

Note: Displayed is the cumulative distribution function of individual's general risk willingness in the pre-experimental study. Data base on an eleven point risk-willingness scale from 0 to 10 , with 0 meaning not at all risk loving and 10 very much risk loving.

Table 10: Self-Reported Risk Willingness and Full-time employment

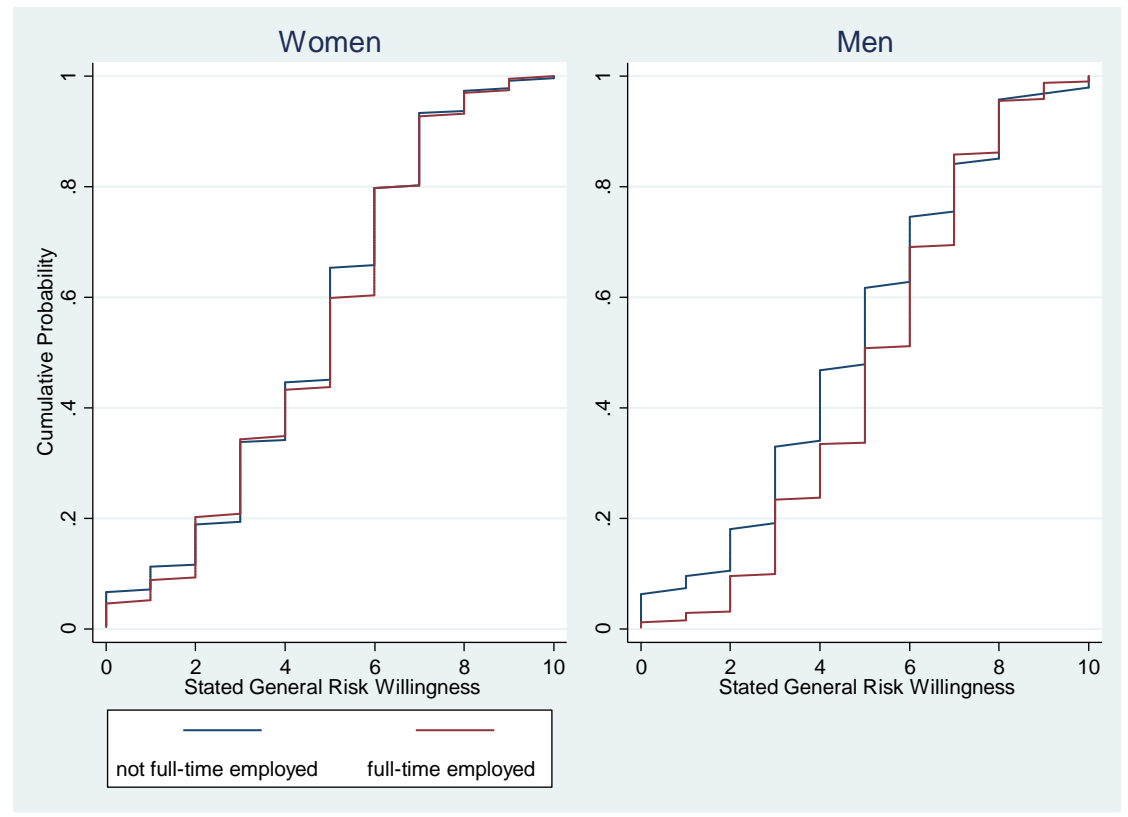

Note: Figure reports cumulative distribution function of self-reported risk willingness of our full-time (FT) employed female experiment subjects. Risk scores are self-reported in the pre-experimental study on an eleven point risk-willingness scale from 0 to 10, with 0 meaning not at all risk loving and 10 very much risk loving in general. Tests reveal an insignificant relationship for women: Pearson Chi2 $(1)=6.104, \mathrm{p}=0.806$, Spearman's rho $=0.021, \mathrm{p}=0.673$, a weak significance for men: Pearson Chi2 $(1)=17.129, \mathrm{p}=0.072$, Spearman's rho $=0.115, \mathrm{p}=0.021$. 
Figure 16: Average Marginal Effect of Same-gender on Competition Entry Decisions Depending by Individual Risk Score

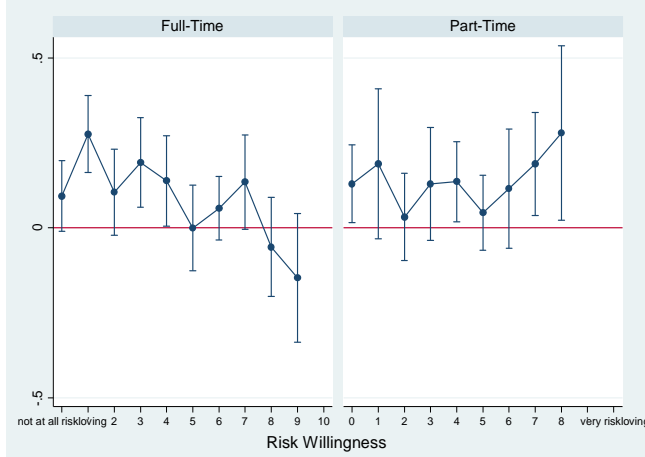

Note: Displayed are average marginal effects of a same-gender setting on the decision to enter competition (vector of (0-1) within $95 \%$ confidence intervals depending on the level self-reported risk-willingness and whether women are full-time or part-time employed. Bases is Model (10) of Tables 11 and 12 

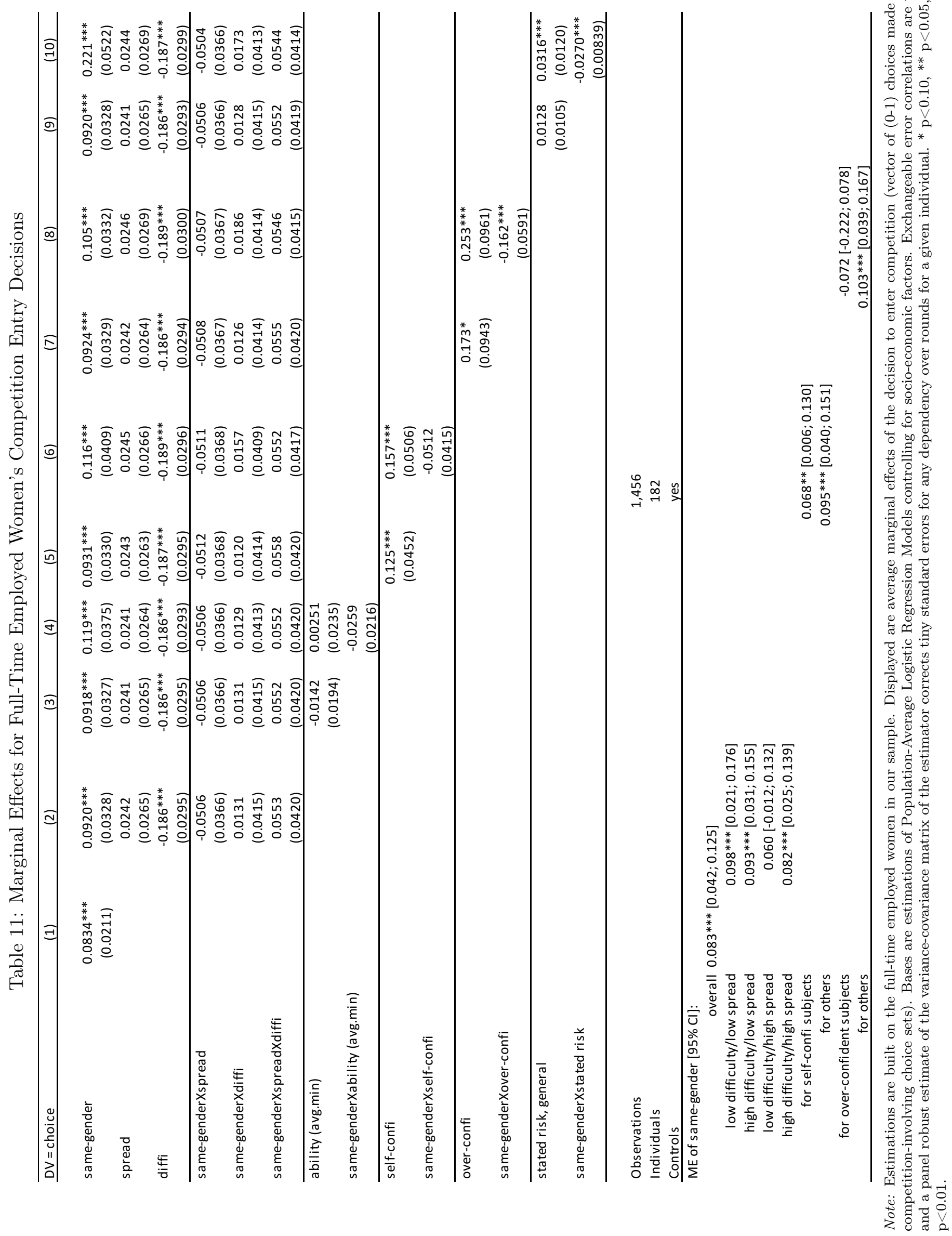

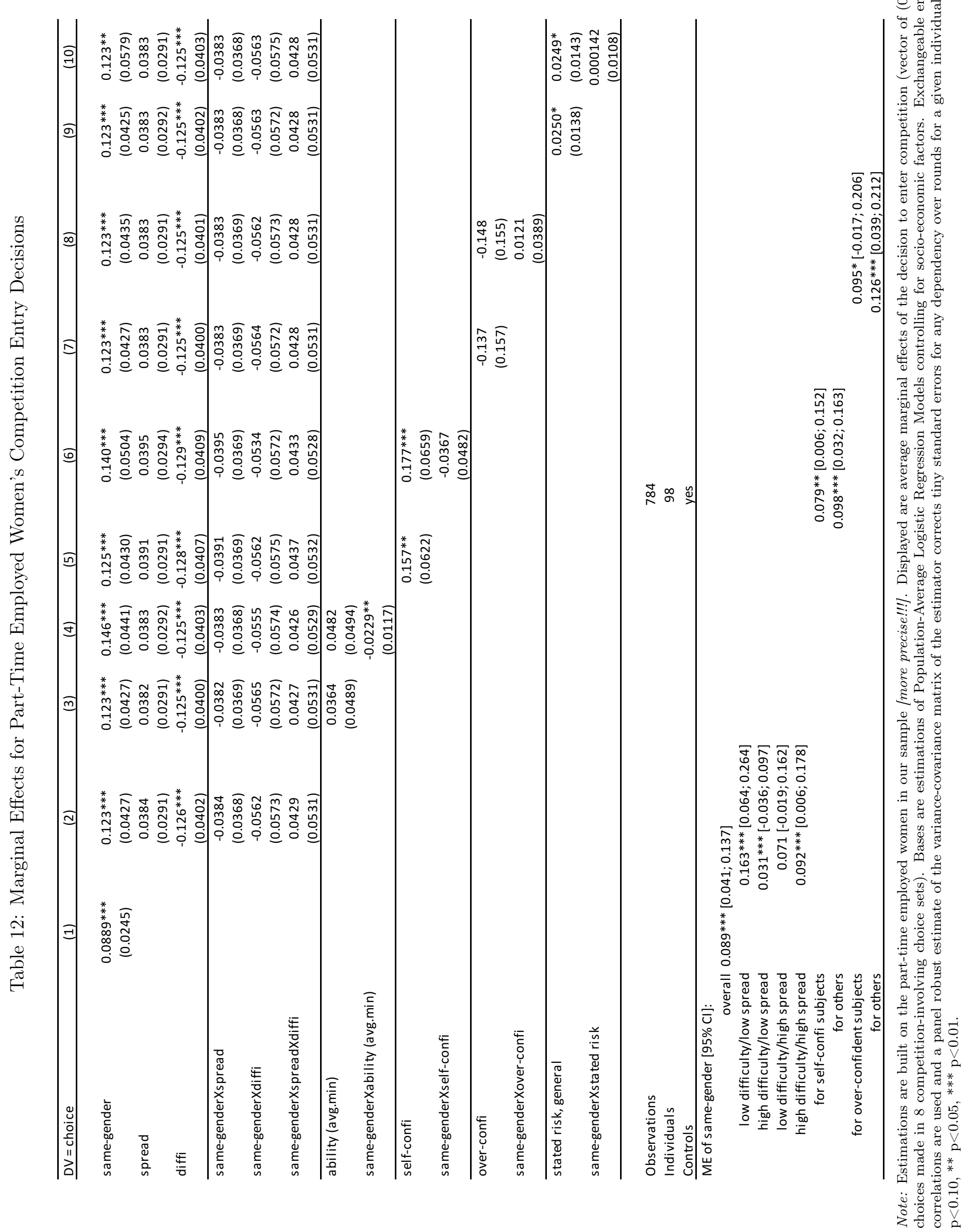